Check for updates

Cite this: RSC Adv., 2021, 11, 7981

\title{
Advantages, limitations, and future suggestions in studying graphene-based desalination membranes
}

\author{
Stefania Castelletto (D)*a and Alberto Boretti (D)*b \\ The potential of novel 2D carbon materials such as nanoporous single-layer graphene and multilayer \\ graphene oxide membranes is based on their possible advantages such as high water permeability, high \\ selectivity capable of rejecting monovalent ions, with high salt rejection, reduced fouling, and high \\ chemical and physical stability. Here we review how the field has advanced in the study of their \\ performances in various desalination approaches such as reverse osmosis, forward osmosis, \\ nanofiltration, membrane distillation, and solar water purification. The research on making high- \\ performance graphene membranes which started with reverse osmosis applications is seemingly \\ evolving towards other directions.
}

Received 12th January 2021 Accepted 8th February 2021

DOI: $10.1039 / \mathrm{d} 1 \mathrm{ra00278c}$

rsc.li/rsc-advances used are MED (7\%), electrodialysis (3\%), and nanofiltration (NF) $(2 \%)$.

The RO process, comprising over $60 \%$ of the current desalination capacity, uses an external positive hydraulic pressure, above the osmotic pressure, to pass a large volume of water with dissolved salt molecules through a semi-permeable membrane. $\mathrm{RO}$ is regarded as an efficient technology for seawater desalination from an energy perspective. It is used as a reference to benchmark any other desalination technology. RO energy use has reduced in the past four decades, ${ }^{5}$ owing to some technological perfections such as mainly the use of higher permeability membranes, the introduction of systems recovering energy, and the adoption of pumps of high efficiency. RO is combined with other pretreatment processes to reduce energy costs and membrane fouling. However, this technology still requires the improvement of the desalination capacity necessitating improved membranes with higher salt rejection and higher permeability, ${ }^{1}$ as well as more resistance to chemicals used for limiting fouling. The energy use for seawater RO is estimated in the range 2.5 to $4.0 \mathrm{~kW} \mathrm{~h} \mathrm{~m}{ }^{-3}$, 6,7 with higher values of approximately 3.5 to $4.5 \mathrm{~kW} \mathrm{~h} \mathrm{~m}^{-3}$ when related to the realscale seawater RO plant. The energy need, in this case, includes pre-treatment and post-treatment procedures. ${ }^{7}$ Overall, there is still a high energy necessity for seawater RO desalination in actual plants, therefore the energy and capital cost are deemed necessary to be reduced.

Membranes for water purification are considered a key technology to advance several desalination methods. Present and prospects of membranes for seawater desalination are discussed in Amy (2017). ${ }^{8}$ As such next-generation membranes were proposed initially based on computational molecular studies, to improve the cost, energy management, selectivity, and permeability of the current desalination methods. ${ }^{9}$ Graphene and related materials are among the most promising and
${ }^{a}$ RMIT University, Melbourne, Australia. E-mail: stefania.castelletto@rmit.edu.au ${ }^{b}$ Prince Mohammad Bin Fahd University, Al Khobar, Saudi Arabia. E-mail: deanshipofresearch@pmu.edu.sa 
received significant attention in terms of recent publications., ${ }^{\mathbf{1 , 1 4}}$ Here the reasons to explore the use of graphene, a material that can potentially deliver the higher permeability coupled to higher rejection needed in RO, and may also help with other membrane processes.

In RO the separation process is driven by a hydraulic pressure higher than the osmotic pressure. The hydraulic pressure is applied to oppose the osmotic pressure, which is inducing the water flow towards the lower salt concentration side of the membrane. Forward osmosis (FO) conversely is an emergent process in which the osmotic pressure drives the water from low to high salt concentration. Membrane development can impact the mostly used RO processes, but also other less commercially available methods such for example $\mathrm{FO},{ }^{\mathbf{3 1 4}, \mathbf{1 5}}$ and membrane distillation (MD) ${ }^{16},{ }^{17}$.

Relevant membrane principle of operation for water purification and desalination include, in addition to RO and FO, microfiltration (MF), nanofiltration (NF), ultrafiltration (UF), $\mathrm{MD}$, and ion exchange membranes. ${ }^{9}$ The separation of the ions in solution in MF, UF, NF membranes can be based on size exclusion mechanisms, due to the different sizes of molecules and other impurities that are not passing through the membranes' pores. Additionally, exclusion or attraction can be due to ions interaction with the membrane surface. In MD the principle that permits separation is hydrophobicity of the membrane. MD uses the porous and hydrophobic membranes only as support for the vapor-liquid interface and does not contribute to actual separation performance, as the separation occurs due to phase-change. Electrical polarity is the separation principle of ion-exchange membranes.

In this work, we will discuss advanced membranes with higher permeability in general, highlighting the theoretical advantages. Then, challenges and opportunities are discussed first for graphene-based membrane designs, and graphene membranes based processes. We discuss graphene-based membranes, nanoporous graphene (monolayer), graphenebased frameworks (stacked multi-layer), and novel graphenebased membranes. Finally, we cover graphene-based membranes for RO water desalination, and alternative graphene-based membranes process, from FO to MD, pervaporation, and solar desalination.

\section{Theoretical advantages of higher permeability membranes}

A membrane is a selective barrier separating a feed stream into a retentate and a permeate portion. Graphene has major theoretical advantages compared to alternatives because of its higher permeability.

\subsection{Advantages from hydrodynamic and solution-diffusion models}

Simple models can be used to explain the advantages of graphene.

The water flow, $J_{\mathrm{w}}$, through the RO, FO, NF, and membranes is generally described by the hydrodynamic model ${ }^{18}$

$$
J_{\mathrm{w}}=A(\Delta P-\Delta \pi)
$$

where $\Delta P$ is the hydraulic pressure difference across the membrane, $\Delta \pi$ is the osmotic pressure difference across the active layer, and $A$ is the water permeability.

According to the classical hydrodynamics theory described by Hagen-Poiseuille the water permeation flux is

$$
J_{\mathrm{w}}=\varepsilon r^{2} \Delta P / 8 \mu d
$$

where $\Delta P$ is the difference in hydraulic pressure, $\varepsilon$ is the surface porosity, $r$ is the effective pore radius, $\mu$ is the liquid viscosity, and $d$ is the thickness of the membrane. Therefore, high permeation flux is characterized by thin membranes.

$J_{\mathrm{s}}$ representing the flux of salt is given by the following simplified formula ${ }^{18}$

$$
J_{\mathrm{s}}=B \Delta c_{\mathrm{s}}
$$

In the above equation, $B$ is the salt permeability constant and $\Delta c_{\mathrm{s}}$ is the solute concentration difference.

The performances of the membranes are typically given in terms of A and B. $\Delta \pi$ is the central constraint of FO and RO membranes:

- $\Delta P>\Delta \pi$ in $\mathrm{RO}$,

- $\Delta P=0$ in FO.

- $\Delta \pi$ is negligible in MF and UF membranes.

While these transport equations certainly hold for all membrane types together (MF, UF, RO, FO), however, (1) to (3) does not differentiate between the different types of membranes. In MF and UF membranes $\Delta \pi$ is negligible simply because the MF and UF membranes are not selective to salt.

Another simple model that applies to the non-porous membranes only is the solution-diffusion model.9,19 The processes in graphene-based membranes are only in part described by these simple models while requiring molecular simulations.

\subsection{Other theoretical advantages of graphene}

The optimal separation performances can be achieved for ultrathin membranes to increase the water permeability, for an ultraselective membrane to maximize salt rejection, being mechanically strong to withstand membrane breakdown. Further, the membranes should be highly resistant to the chemicals delivered to limit the membrane biofouling. ${ }^{20}$

The main benefits attributed to the graphene-based membrane are to be very thin, selective, resistant to chlorine, and have antimicrobial properties..$^{21-23}$ The thickness of the membrane is due to the nature of a single layer or a few layers of material that permits higher permeability or water flow. The selectivity can be attributed to ultra-small pore sizes (subnanometer), interlayers separation and pores chemical functional groups, which can provide electrostatic interactions with ions. The pores' chemical functionalization can also modify the water flow, for example, reduce it in hydrogenated pores, and increase it in hydroxylated pores. ${ }^{24}$ Similarly, the water flux in interlayered graphene-based membranes can be reduced or 
increased depending on the hydrophobicity of the interlayers nanochannels, accelerating the water flow within the membrane. The selectivity of graphene membranes can be in principle adjusted by tuning the pores sizes or their interlayers spacing for multilayer membranes. However, the controlled formation of uniform defect-free sub-nanometer pores (radius of $<0.45 \mathrm{~nm}$ ) as well as the interlayers distance control at the same level, is one of the current obstacles, and the so-far demonstrated performance of these novel membranes is still a trade-off between permeability and selectivity, as for traditional membranes. This trade-off will be detailed in the following sections for different specific graphene-based membranes type. The other aspects which are in principle the advantages such as chlorine resistance and anti-bacterial properties will be also reviewed.

According to Cohen-Tanugi and Grossman (2012), ${ }^{24}$ and Cohen-Tanugi and Grossman (2015) ${ }^{25}$ the current most permeable RO membranes based on polyamide (PA) thin-film composite (PA-TFC), have only achieved a moderate higher permeability compared to 20 years ago and they still incur damage due to chlorine used for disinfection. As the water flow through a membrane is inversely related to its thickness $d$, it has been concluded $^{24}$ that due to the atomic thickness of single-layer graphene $(d \approx 0.34 \mathrm{~nm})$, it can provide a much larger water permeability compared to the PA-TFC membranes $(d \approx 100 \mathrm{~nm})$. Besides, graphene is more chemically resistant to chlorine than PA deterring membrane fouling with reduced degradation, and both graphene and graphene oxide (GO) have shown antimicrobial properties, reducing membrane biofouling.

\subsection{Graphene membranes within mainstream desalination processes}

It has been claimed that the advance of more permeable and thinner membranes can decrease the energy consumption and related costs in the RO desalination process. Cohen-Tanugi and Grossman (2012) ${ }^{24}$ consider the pressure reduction as the main argument to reduce energy consumption in RO by adopting the graphene membrane. In Cohen-Tanugi and Grossman $(2012)^{24}$ it has been shown computationally that by improving three times the membrane permeability in RO, it decreases the required pressure by $44 \%$ and $63 \%$ for seawater and brackish water RO plants, respectively, reducing the energy consumption by 15 and $46 \%$. However, in current RO systems, the required pressure is nearly approaching its thermodynamic limit, as such further reduction of the applied pressure may not significantly improve the membrane performance. ${ }^{10}$ As the RO process is not hydraulically, but rather thermodynamically constrained, ${ }^{26-28}$ the usage of higher-permeability desalination membranes has been deemed not significant in terms of a commercial advantage since the current production membranes are sufficiently permeable to convene low-energy request. Specifically, in Elimelech and Phillip (2011), ${ }^{29}$ the authors state that, for seawater RO desalination, utilizing more permeable membranes, as an example based on aquaporin, graphene, and carbon nanotubes, cannot significantly reduce the current RO energy consumption, which is not much higher than the theoretical limit. Elimelech and Phillip (2011) ${ }^{29}$ outlooks at the current RO membrane technology, which is already close to the theoretical limit in terms of energy consumption, and it is presently not limited by high pressure. They argue that a more permeable membrane would not further reduce the $\mathrm{RO}$ desalination costs.

As an example, an ideal RO system operating at the thermodynamic limit (ideal devices) recovering $50 \%$ of seawater requires a minimum energy of 1.6 to $1.8 \mathrm{~kW} \mathrm{~h} \mathrm{~m}^{-3}$, while reported energy consumption by optimized seawater RO systems have an energy consumption of $\sim 2.2 \mathrm{~kW} \mathrm{~h} \mathrm{~m}^{-3} \mathbf{.}^{\mathbf{1 , 1 0}}$ As such energy efficiency and cost reduction of an RO desalination cycle should be rather pursued in pre-and post-treatment processes, critical to reducing the decline in selectivity and flux caused by fouling from inorganic and organic molecules. ${ }^{30}$ For example, eliminating the pretreatment process by developing foulingresistant membranes with surface properties that inhibit the adhesion of miscellaneous foulants would remarkably lower the energy consumption and costs. In this direction, examples of PA TFC membranes with GO for RO were fabricated ${ }^{31}$ (denominated thin film nanocomposite, TFN, membranes). This reference applies $\mathrm{TiO}_{2}$ nanoparticles and GO which were layer-bylayer self-assembled onto PA RO membrane surfaces to improve the membrane durability making them more resistant to chlorine and biofouling. Some of these critical aspects in RO have been recently investigated also by using graphene-based membranes and will be discussed in the next sessions.

FO is a purely osmotically or chemically driven semipermeable membrane process. It is a natural filtration process where water molecules are spontaneously diffused through the pores of a membrane due to the solutes' concentration gradient. The low concentration salinity (feed) water permeates from the higher concentration solution (draw), having an osmotic potential higher than that of the feed solution, while the hydraulic pressure $\Delta P$ difference at the membrane is negligible. The feed solution becomes more concentrated while the draw solution becomes more diluted. As such the FO final solution is not freshwater, but rather a diluted draw solution, requiring a secondary separation process. While the desalination with $\mathrm{FO}$ as an initial pretreatment process for RO (FO-RO) is more energy-intensive than seawater desalination with $\mathrm{RO},{ }^{32}$ nevertheless the use of a FO draw solution based on low-grade waste heat or solar energy can potentially lower the cost of desalination. ${ }^{33,34}$ FO is also less susceptible to fouling due to low irreversible membrane fouling and GO membranes were employed in FO. ${ }^{\mathbf{1 4 , 3 5}}$ Progress on the application of graphene-based membrane to FO indicates that the performance is highly dependent on the fabrication methods to fabricate an ultrathin GO membrane. Illustration of various membrane processes namely $\mathrm{RO}, \mathrm{NF}, \mathrm{UF}, \mathrm{MF}$, and traditional particle filtration, with an increase of membrane pore size, is presented in Lee, Elam, and Darling (2016). ${ }^{36}$

\section{Graphene-based membrane designs}

Graphene comprises of $\mathrm{sp}^{2}$-bonded carbon atoms in twodimensional few-atoms thick hexagonal patterns, mono- 


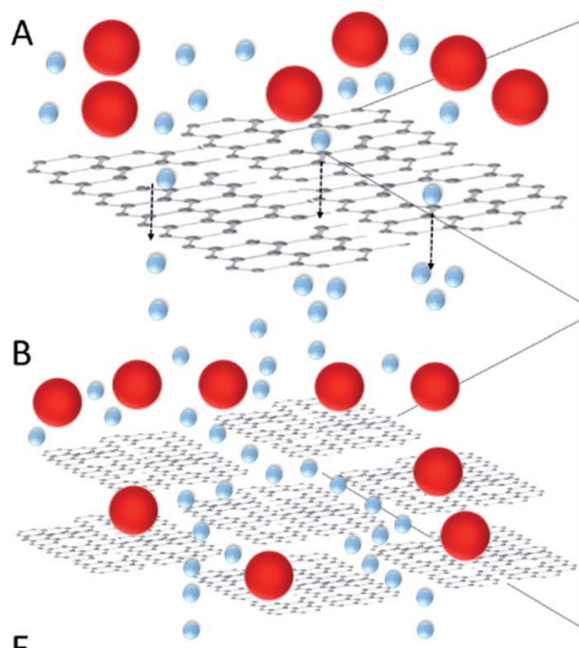

$E$

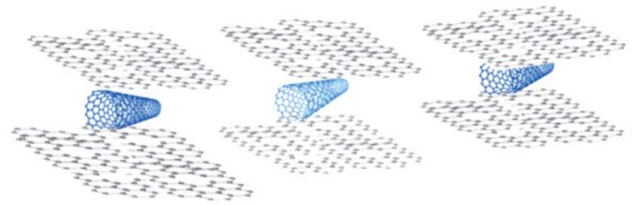

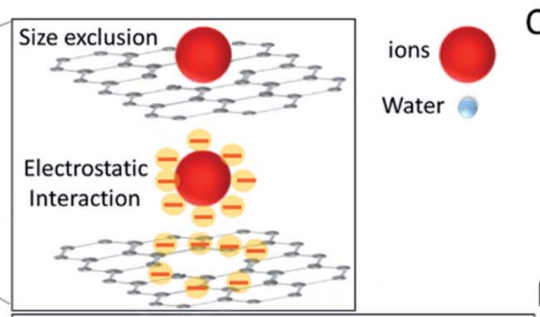

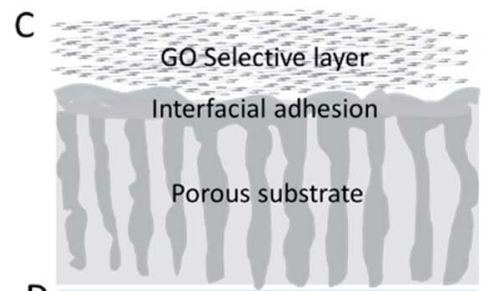

D

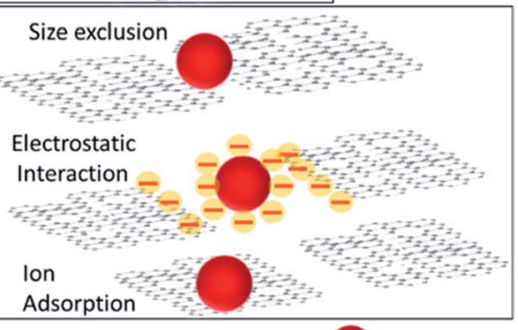

$\mathrm{F}$
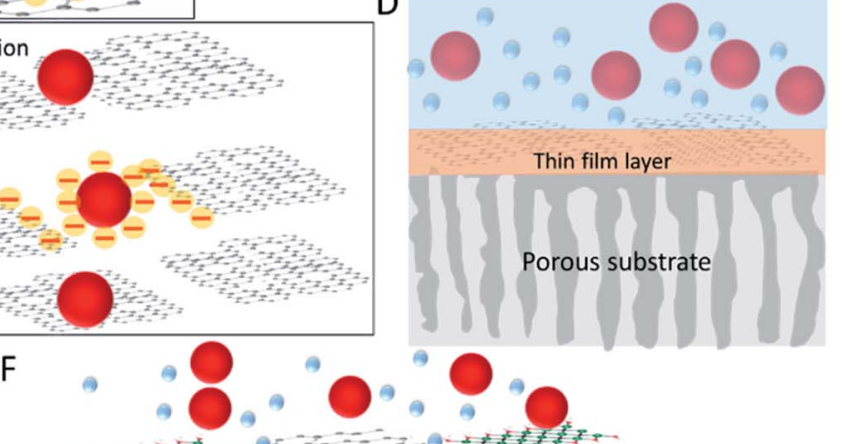

(1)
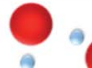

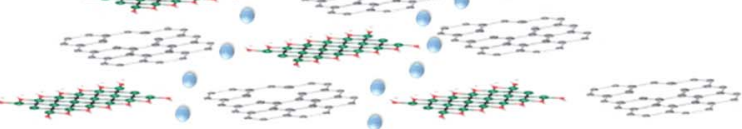

Fig. 1 Schematics of the principles of major groups of graphene membranes design. (A) Nanoporous Graphene (NPG). (B) Graphene oxide (GO) interlayers membranes. (C) GO interlayers on porous substrate. (D) GO into polymers matrix thin layer composite on porous substrate. (E) GO reinforced with carbon nanotubes hybrid membranes. (F) GO and MXene interlayers hybrid membranes.

layered (single atom thick), and few-layered graphene. Graphene provides many relevant mechanical, thermal, catalytic, physical, and optical properties in many areas of science and engineering, due to its $\mathrm{sp}^{2}$ covalent bonds and the electrons' mobility. Among its remarkable properties, graphene comprises a very high mechanical strength and elasticity, a tunable bandgap, excellent thermal, and electrical conductivity $(5300 \mathrm{~W}$ $\mathrm{m} \mathrm{K}^{-1}$ and $\left.2000 \mathrm{~S} \mathrm{~cm}^{-1}\right){ }^{37}$ These properties make graphene one of the strongest, lightest, the most conductive material, superior to diamond and steel.

GO is prepared by exfoliation of graphite and by oxidization when dispersed in basic solutions. ${ }^{38,39}$ As such, it is considered a graphene derivative, but it is less expensive and easier to produce. GO comprises of single or few layers, containing oxygen and oxidized functional groups such as carboxyl, hydroxyl, and epoxy groups acquired during oxidation, mainly on the edges of flakes. ${ }^{40,41}$ Reduced graphene oxide (rGO) is generally the final product obtained from GO; owing to imperfect reduction, hydroxyl and carboxyl groups remain on the edge of the graphitic sheets. Fabrication methods using less expensive processes are required to achieve a higher yield of GO and rGO. Many applications see the formation of composite material obtained by mixing GO with polymers or other nanomaterials. The resulting composite material presents improved properties such as tensile strength or elasticity and conductivity.

A single-layer or double layer of graphene is hydrophobic and impermeable to water and cannot be used directly as a separation membrane. GO is hydrophilic while maintaining some hydrophobicity. GO can constitute nanomembranes permeable to water while impermeable to impurities, salts, or bacteria. ${ }^{18}$

Graphene-based membranes mostly address the requirements for applications in NF, RO, and FO due to their ultrasmall thickness, pores of very small diameters, and small relative distances, improving the water flux across the membrane, which is inversely proportional to the thickness of the membrane in the pressure-driven process (see eqn (2)).

While nanopores can be generated in the graphene-based membrane using various methods such as electrons, ions implantation, and chemical and laser UV etching on the membrane surface, ${ }^{42-44}$ a technological challenge remains in achieving the holes controlled locations and density in the membrane.

Many recent literature reviews ${ }^{1,9,10,12,21,23}$ have discussed graphene-based membranes summarizing some of the key performances based mostly on computational studies. These studies have suggested the advantages of great permeability and selectivity, also considering the molecular transport of water through the membranes. It has been determined that engineering of the permeability of water and solute in these membranes' may not be controllable.

Fouling control is expected to be a key advance of these membranes, however high separation and selectivity performances are hardly coupled to improved water flow and reduced fouling.

These novel membranes promise extraordinary permeation properties coupled with antifouling, antibacterial, and chemical resistance properties, which were already observed in their composites. $^{45}$ 
Fabrication methods of the porous graphene, or composites and laminates of graphene, are discussed in Liu, Jin, and $\mathrm{Xu}$ (2015). ${ }^{46}$ Graphene or GO have been combined in many studies mixed with polymers on ceramics support to enhance the mechanical characteristics of conventional composite membranes.

Graphene-based water desalination membranes are distinguished into three main types: nanoporous graphene (NPG), GO-based frameworks including interlayer nanochannels in GO flakes multilayers, GO-doped polymer membranes. Other graphene membrane structural ideas are also being explored as reviewed in Boretti et al. (2018). ${ }^{10}$ In Fig. 1, the main principles and major groups type of graphene-based membranes are illustrated. Although a range of often unique demonstration of variant or completely alternative type of these schemes are also available and will be mentioned, even if not comprehensively, in the next Sections.

In Table 1 we list the type of graphene-based membranes and their composite/hybrid design with the advantages and disadvantages detailed in the next sections.

NPG and GO-frameworks membranes serve as selective single layer or multilayers nano-channels operating as molecular filters with an exclusion based on the size of the unwanted solutes and other aspects such as hydrophobicity and charge exclusion based on functional groups at the nanopores or nanochannels. Details of NPG and GO frameworks fabrication as freestanding and supported membranes are provided in Mahmoud et al. (2015) ${ }^{22}$ and Anand et al. (2018), ${ }^{12}$ showing their excellent properties in water desalination membranes. The challenges currently outlined in NPG and GO membranes consist in achieving a controlled fabrication of the nanopores, in the identification of the mass transport mechanisms across the nanosheets, the production of membranes mechanically stable over a large-scale, the reduction of fouling, and the associated flux decline.

While a full description of GO-doped polymer membranes is provided in Anand et al. (2018), ${ }^{12}$ the manufacture and current interpretation of the mechanisms of mass transport in NPG and GO laminates are reviewed in Sun and Wang (2016). ${ }^{47}$

Based on the above reviews, a clear improvement in graphene and GO membranes versus production polymer and ceramic-based membranes was concluded regarding better permeability of water or mass transport.

Further information about the membranes is given in the following subsections where three main structures are considered:

(3.1) monolayer nanoporous,

(3.2) stacked multilayer and graphene-based frameworks,

(3.3) more complex membranes including graphene layers.

\subsection{Nanoporous graphene (monolayer)}

Single-layer graphene represents the simplest graphene-based desalination membrane. A single-atomic layer graphene membrane with fabricated sub-nanometer pores, used as RO membrane, is described in Cohen-Tanugi and Grossman (2012). ${ }^{24,48}$ This work is purely computational.
3.1.1 Separation and selectivity and permeability. The saltwater, subjected to high pressure, is separated at the membrane where water molecules are passing through while the salt ions are blocked. Water can penetrate the subnanometer size pores as opposite to salt ions which are larger than the water molecules. As such filtration occurs primarily via size exclusion or in the case of functionalization of the pores via electrostatic interactions with the ions. O'Hern $(2012)^{49}$ describes the separation mechanism of a single-layer graphene membrane with nanopores of controlled size and a multilayer GO membrane composed of piled GO sheets.

Computational results obtained for hydrogenated and hydroxylated graphene pores were proposed in ref. 24 for charge exclusion. Most of the works that have shown advantages with graphene membranes are computational works. As discussed later, different is the evidence that can be inferred from experiments, where membranes have generally performed much less than the expected, because of real-world issues simply ignored in the speculative and simplistic computational models.

NPG membranes were projected ${ }^{24}$ to have a greater coefficient for permeability than current TFC RO membranes due to the ultralow thickness of the membrane, with complete salt rejection for $0.45 \mathrm{~nm}$ diameter hydroxylated pores.

3.1.2 Scalability impacting selectivity and mechanical stability. After this initial work, it has been determined that scaling up of NPG membranes can be tremendously challenging, ${ }^{9,42,49-52}$ due to the requirement of the fabrication of a defect-free large area of single-layer graphene, in addition to the scalable creation of regularly sized nanopores. ${ }^{9}$ It has been shown that to implement a membrane for desalination, the single-layer graphene requires to be shifted to a substrate with 5 $\mu \mathrm{m}$ larger holes, as an example of silicon nitride. ${ }^{\mathbf{4 2}}$ This process introduces morphological defects in the membrane.

Graphene membranes' main objective is the improvement of ion selectivity together with maintaining high water permeation rates possibly higher than the ones currently achieved in RO systems, which is in the range of 2 to $3 \mathrm{~L} \mathrm{~m}^{-2} \mathrm{~h}^{-1} \operatorname{bar}^{-1}(8 \times$ $\left.10^{-12} \mathrm{~m} \mathrm{~Pa}^{-1} \mathrm{~s}^{-1}\right)$. However, the graphene single layer seems to have very high selectivity only in principle as the defects introduced during the transfer on another substrate reduce the selectivity for smaller molecules like salts, which pass through the membranes.

A study of the optimal pore density and size is reported in Surwade (2015)..$^{42}$ A higher density of pores of $\sim 10^{12} \mathrm{~cm}^{-2}$ corresponding to the pore size of 0.5 to $1 \mathrm{~nm}$ provides a better membrane performance up to the point of inducing mechanical instability. When the NPG membrane was fabricated with the minimum number of defects, it exhibits a salt rejection of nearly $100 \%$ while maintaining water flow, under a hydraulic pressure difference, of up to $10^{6} \mathrm{~g} \mathrm{~m}^{-2} \mathrm{~s}^{-1}$ at $40{ }^{\circ} \mathrm{C}$. Even if the driving force is however large and not certainly $1 \mathrm{~atm}$, this value for the transport flux is particularly high. Osmotic pressure difference driven water fluxes of less than $70 \mathrm{~g} \mathrm{~m}^{-2} \mathrm{~s}^{-1} \mathrm{~atm}^{-1}$ $\left(\sim 6.8 \times 10^{-10} \mathrm{~m} \mathrm{~Pa}^{-1} \mathrm{~s}^{-1}\right)$ were found.

While Surwade $(2015)^{42}$ reports very high water fluxes of up to $10^{6} \mathrm{~g} \mathrm{~m}^{-2} \mathrm{~s}^{-1}$ at $40{ }^{\circ} \mathrm{C}$, they measured the pervaporation of 

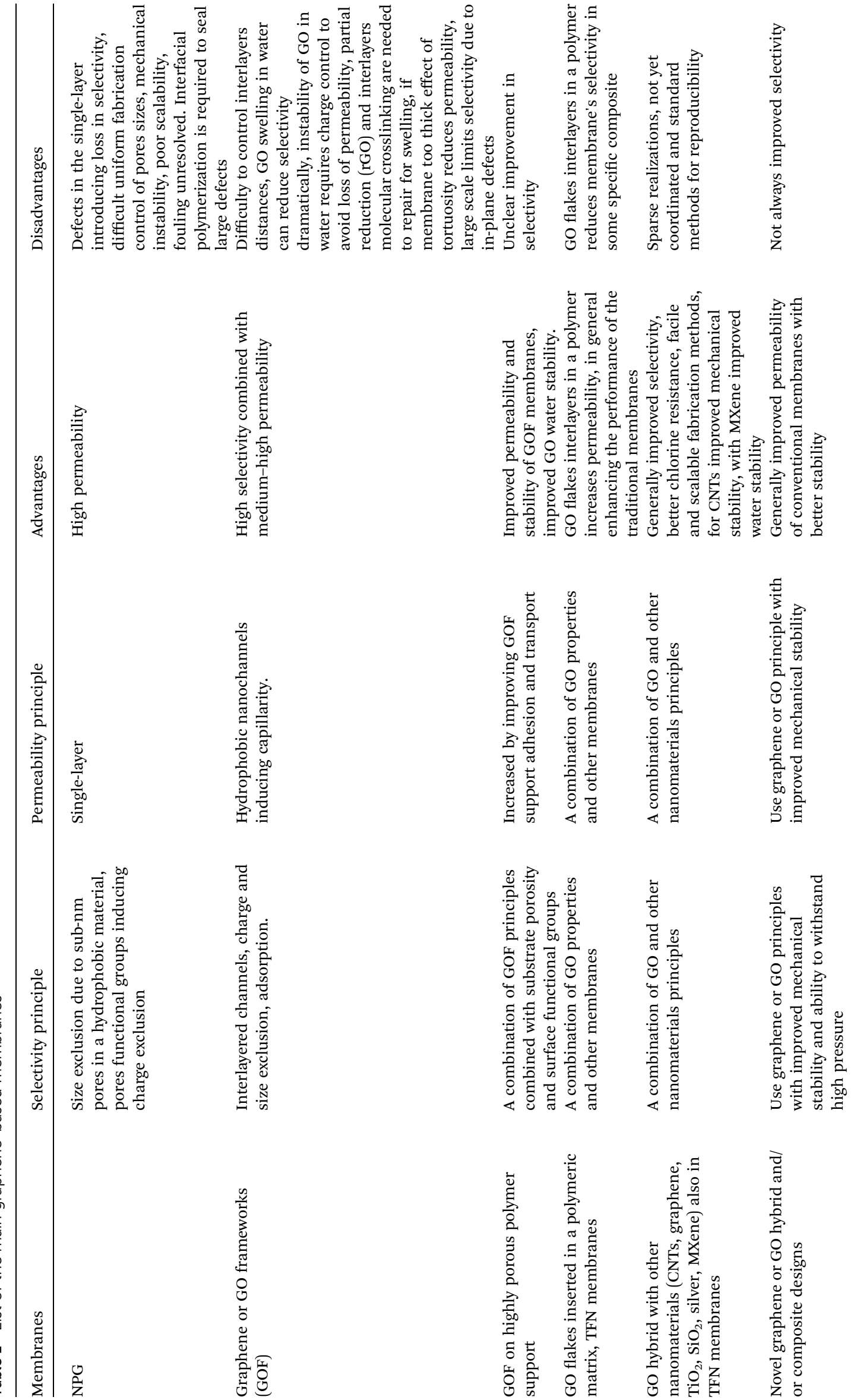
water rather than water transport. The demonstration of gas, liquid, and water vapor permeances in graphene resulting much higher compared to the one observed in larger thickness membranes was already reported in Celebi et al. (2014), ${ }^{53}$ where also it was observed that capillarity prevents water transport when only one side of the membranes is wetted.

Another attempt in transferring single-layer graphene provided a water flux of $500 \mathrm{~L} \mathrm{~m}^{-2} \mathrm{~h}^{-1}$ (ref. 54) at 10 bar of pressure difference, and operating up to $50 \mathrm{bar}$, however, the salt rejection was impeded by unsealed defects occurring during the transfer of the graphene.

Attempts to fabricate larger sizes of a few micron membranes to improve scalability for real applications can be found in O'Hern (2012) ${ }^{49}$ and O'Hern (2014). ${ }^{51}$ Transmission Electron Microscopy (TEM) grids were used as mechanical support to fabricate suspended single-layer graphene, ${ }^{55}$ while oxygen plasma treatment was used for creating nanopores. The self-supporting graphene had areas from 70 to $6.5 \mu \mathrm{m}$ wide and was tested for water desalination under the driving force of $1 \mathrm{~m}$ column of salty water. They achieved water permeation of $1.6 \times$ $10^{7} \mathrm{~L} \mathrm{~m}^{-2} \mathrm{~h}^{-1} \operatorname{bar}^{-1}\left(\sim 5 \times 10^{-5} \mathrm{~m} \mathrm{~Pa}^{-1} \mathrm{~s}^{-1}\right)$ and $\mathrm{NaCl}$ rejection rate of $\sim 76 \%$ with a membrane-active area of $\sim 2.8 \times 104 \mu^{2}{ }^{25}$ This is almost a factor of 5 better than what previously achieved from a $5 \mu \mathrm{m}$ single-layer graphene membrane, ${ }^{42}$ however with a much lower salt rejection rate. This was possible using porous mechanical support to increase the break strength of large-area suspended graphene and to limit the number of cracks, pinholes, wrinkles, and defects in the membrane impeding to apply $\sim 50-80$ bar pressure, essential for water desalination. It must be mentioned that Kazemi, Hosseini, and Abdi $(2019)^{55}$ do not provide a detailed description of their experiments, and the reported results may not be reliable, because it has not been reproduced $\left(10^{7} \mathrm{~L} \mathrm{~m}^{-2} \mathrm{~h}^{-1} \mathrm{bar}^{-1}\right)$.

It can be concluded that the potential of a single-layer graphene membrane is still limited by the creation over a macroscopic area of controllable sub-nanometer pores' size distribution on pristine graphene with the minimum of acquired defects.

Currently, when fabricating a centimeter-scale single layer of graphene on a substrate, tears and extrinsic defects in the range of 100-200 nm can be created in the final device, responsible for leaking. Also, even if no tears are introduced, intrinsic defects from the growth process with sizes of 1-15 $\mathrm{nm}$ are already present, preventing the effectiveness of sub-nanometercontrolled pore fabrication. A sealing process at different defect scale level has been proposed in O'Hern $(2015)^{52}$ to reduce both transfer and growth of uncontrollable defects in the membrane. After sealing, water transport and salt rejection were tested under FO, obtaining water transport values like the ones obtained in current RO membranes. As per rejection rates, while satisfactory for $\mathrm{MgSO}_{4}$, dextran, and a red dye, $\mathrm{NaCl}$ was permeable through the imperfect sealing of the defects. ${ }^{52}$ This indicates the sealing may not be successful to achieve salt rejection.

More recently a novel method with pore formation followed by interfacial polymerization was achieved for sub-nanometer scale separations in large-area atomically thin graphene membranes. ${ }^{56}$ Here, size-selective interfacial polymerization after high-density nanopore formation in graphene is used to seal larger defects, macroscopic tears and preserves the smaller pores created by mild UV/ozone oxidation. The permeability of water and salt rejection were $\sim 1.1 \times 10^{-11} \mathrm{~m} \mathrm{~Pa}^{-1} \mathrm{~s}^{-1}$ and $97 \%$ in FO using a scalable centimeter-scale nanoporous graphene membrane. ${ }^{56}$

Achtyl $(2015)^{57}$ claims that while proton transport through ideal single-layer graphene cannot take place due to a high energy barrier, by creating nanopores or dopants to the membrane, a potential bias can be applied to transfer hydrogen protons. This can be achieved via four carbon vacancies hydroxyl-terminated allowing hydrogen protons to traverse the barrier and reversibly transfer from the water phase throughout graphene. However, this result is conflicting with $\mathrm{Hu}$ et al. $(2014)^{58}$ as proton transport can occur also through pristine graphene.

The recent evolution of graphene membranes involves the combination of graphene with other nanomaterials to provide mechanical stability ${ }^{59}$ where for example nanoporous graphene membrane was reinforced by a network of single-walled carbon

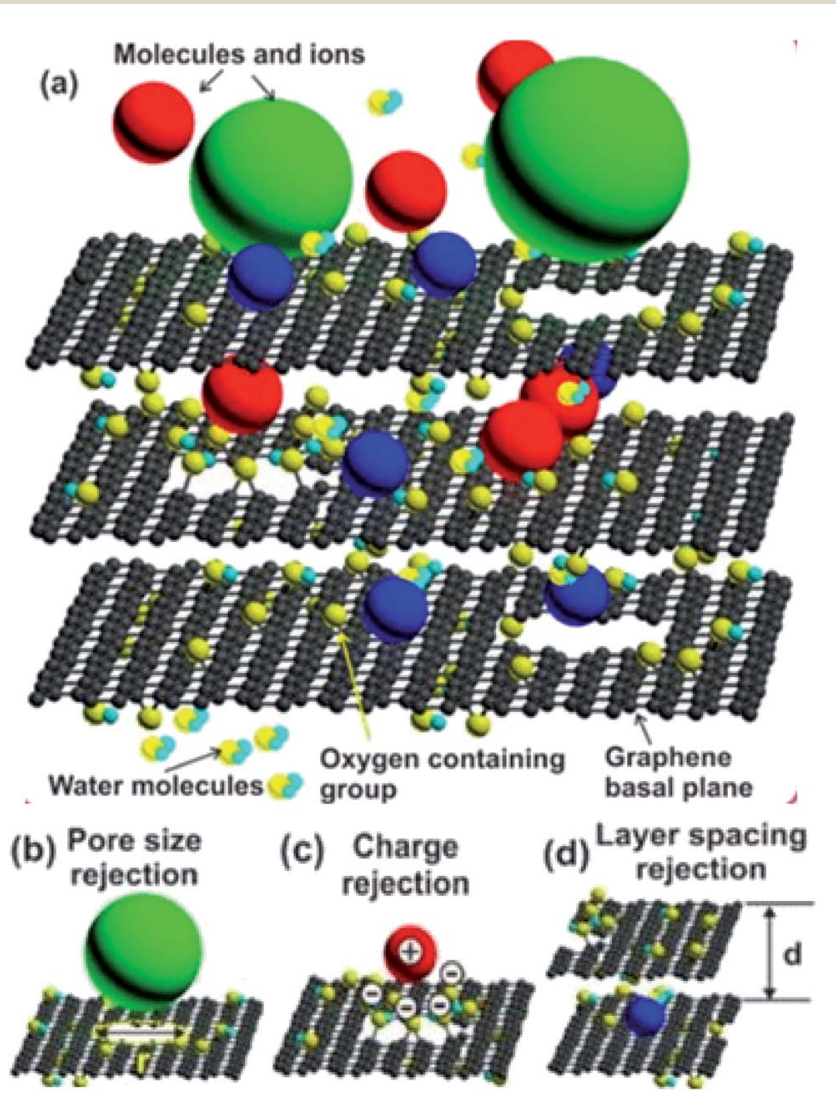

Fig. 2 (a) Drawing representation of molecules and ions traversing a 2D stacked GO flakes with the main transport mechanisms of GO membranes. (b)-(d) Rejection by pore size, charge and layer spacing. ${ }^{61}$ Reprinted (adapted) with permission from (Tieshan Yang, Han Lin, Kian Ping Loh, and Baohua Jia, Fundamental Transport Mechanisms and Advancements of Graphene Oxide Membranes for Molecular Separation, Chemistry of Materials, 2019, 31(6), 1829-1846. DOI: 10.1021/ acs.chemmater.8b03820). Copyright (2019) American Chemical Society. 
nanotubes (SWNTs), which eliminated the propagation of cracks in the material. The membranes showed water flux rates of $\sim 1.1 \times 10^{-10} \mathrm{~m} \mathrm{~Pa}^{-1} \mathrm{~s}^{-1}$ and $98 \%$ salt rejection in FO, among the highest reported using graphene. Another fast mechanism for diffusion of water molecules on the surface of graphenebased on water nanodroplets has been studied by molecular dynamics simulations (MDS). ${ }^{60}$ This can open to other applications than water desalination of the graphene membranes.

\subsection{Graphene-based frameworks (stacked multi-layer)}

The distinction of NPG membranes from graphene-based framework membranes is due to their different structure and form and by the different water flow mechanism. ${ }^{61}$ Graphene framework comprises multilayered graphene, ${ }^{62-65}$ or their functionalized derivatives such as GO. Fig. 2 displays a representation of molecules and ions passing through 2D stacked GO with highlighted the GO membranes' central transport mechanisms. The image proposes in-plane pore size rejection, charge rejection, and inter-layer spacing rejection.

As a result of the limited practicality of single-layer NPG membranes, ${ }^{24}$ multi-layer NPG membranes were studied using MDS, ${ }^{62}$ finding that, while maintaining desalination properties of single-layer graphene, they could have improved features by a controlled division of the layers, and by offsetting the pores between the layers.

3.2.1 Separation and selectivity. Multi-layer graphenebased membranes present a laminar structure containing nanochannels with tunable sizes and specific surface chemistry, providing in principle high selectivity and water flux with characteristic water permeation rate $>500 \mathrm{~L} \mathrm{~m}^{-2} \mathrm{~h}^{-1} \mathrm{bar}^{-1}$ under external pressure for $\mu \mathrm{m}$-thick membranes. ${ }^{66,67}$ However, tested in FO a $66 \%$ of salt rejection and $28.9 \mathrm{~L} \mathrm{~m}^{-2} \mathrm{~h}^{-1} \mathrm{bar}^{-1}$ have been witnessed. ${ }^{68}$

The rejection selectivity is due to the combination of effects due to exclusion of certain size which depends on the spacing between layers of the flakes, on the electrostatic interactions between the charged ions and the charged surface state of the flakes, and on adsorption effects (see the multilayer stacked GO sheets shown in Perreault, Fonseca de Faria, and Elimelech $\left.(2015)^{69}\right)$.

Two-layers of graphene with pores functionalized by fluoride charged negatively and by atoms of hydrogen charged positively were studied by MDS to explore the ion separation of $\mathrm{NaCl}$ dissolved in water. ${ }^{70}$ It was found a preferential selectivity toward $\mathrm{Na}^{+}$and $\mathrm{Cl}^{-}$of the fluoride and the hydrogen pore.

Other few-layers' graphene functionalization methods were studied. For example, after few-layers graphene flakes functionalized with cationic rhodamine $6 \mathrm{G}-\mathrm{R} 6 \mathrm{G}$, the graphene membrane becomes selective of $\mathrm{Hg}^{2+}$ and induces their rejection from water. $\mathrm{Hg}$ is considered a dangerous pollutant in water. $^{71}$

GO Framework (GOF) is a GO-laminated membrane with a fabrication proposed in Joshi (2014). ${ }^{63}$ The separation is determined by the layers' separations estimated at $0.45 \mathrm{~nm}$. A facile and environmentally workable approach to synthesizing rGO is by hydrothermal reduction. ${ }^{72}$ The challenge in the synthesis of GO laminar membranes is the precise subnanometer control of the interlayer of GO laminate. Mi $(2014)^{65}$ shows that water, ions, and molecules smaller than the spacing between GO nanosheets, can permeate across the GO membrane nanochannels, whereas larger elements are stalled. By adjusting the nanochannel size of the GO membrane the separation efficiency can be controlled. ${ }^{65}$ It is essential to be able to perform this fine control to address the selectivity of small molecules. Many different production methods for small samples are proposed, for example..$^{73-76}$ Recent reviews on GO membranes ${ }^{77,78}$ describe their fabrication methods such as vacuum/pressure filtration method, drop-cast, spin-coating, layer by layer (LBL) assembly. One of the most scalable methods is the shear alignment of discotic liquid crystals of $\mathrm{GO}^{74}$

3.2.2 Permeability. Similar to graphene multilayers, GOFs permit fast permeation of water due to the non-oxidized nanochannels. ${ }^{64}$ Capillary driven force and low-friction water flow due to the confinement within $2 \mathrm{D}$ channels produce an unusual high-water flow rate. The channels are surrounded by hydrophobic regions of graphene that are not oxidized inducing water capillarity, as opposite oxygen-containing functional groups of the GO decelerate the water flow between the hydrophilic oxidized graphene flakes due to interaction with the water molecules H-bonding. This interaction between hydrophilic regions and water also causes the swelling of the water-logged membranes, with an increasing decline of the solute rejection capability.

Due to oxidized graphene, GOF membranes slightly enlarge in water, and due to increased interlayer distance $(0.8 \mathrm{~nm})$ exhibit poor separation efficiency, passing salts of less than $0.9 \mathrm{~nm}$ in size, while larger ions or molecules are blocked. ${ }^{64} \mathrm{GO}$ membranes swell in the presence of water inducing interlayer spacing up to $\sim 1.4 \mathrm{~nm}$.

For tested GOF membranes of $5 \mu \mathrm{m}$ thickness, ${ }^{63}$ smaller ions rapidly permeate through the membranes. GOFs in Werber, Osuji, and Elimelech (2016) ${ }^{9}$ show a sharp cutoff with the toolarge size nanochannels for desalination and proved to be unstable in water. Water stability can be achieved by trace multivalent cations. ${ }^{79}$

3.2.3 Interlayer spacing control. To limit and control interlayer spacing is a critical step in GO membranes, which can be achieved by crosslinking GO membranes with various small molecules. ${ }^{78}$ Using MDS the performance of crosslinked GOF membranes was assessed for both water desalination and filtration of bacteria. ${ }^{80}$

In Zheng, Tu, Urban, $\mathrm{Li}$, and $\mathrm{Mi}(2017)^{\mathbf{8 1}} \mathrm{GO}$ membranes tested under a pressure-driven filtration process failed to selectively transport ions, due to a too large interlayer spacing when GO membranes were swollen in water. Numerous efforts to control the interlayer spacing of GO membranes in water have been carried out primarily via partial reduction ${ }^{65}$ and cross-linking. ${ }^{82}$

Cross-linked GO membranes, fabricated with cationic tetrakis(1-methyl-pyridinium-4-yl)porphyrin (TMPyP) by vacuum-filtration, attained a salt rejection of $87 \%\left(\mathrm{Na}_{2} \mathrm{SO}_{4}\right)$ and $30 \%(\mathrm{NaCl})$ and water permeation of $7.5 \mathrm{~L} \mathrm{~m}^{-2} \mathrm{~h}^{-1} \mathrm{bar}^{-1}{ }^{83}$ 
It has been shown challenging to achieve tuning of GO interlayer spacing, ${ }^{\mathbf{8 4}}$ making it difficult to obtain a high salt rejection in a pressured filtration process. Membranes with interlayer spacing from $\sim 9.8 \AA$ to $6.4 \AA$ are demonstrated $^{85}$ using physical confinement, permitting to achieve accurate and tunable ion filtering smaller than the diameters of hydrated ions. The ion permeation, in this case, could be thermally activated limiting the swelling and achieving 97\% rejection for $\mathrm{NaCl}$ and water permeation of $0.75 \mathrm{~L} \mathrm{~m}^{-2} \mathrm{~h}^{-1} \mathrm{bar}^{-1}$.

rGO membranes have also been studied with similar multilayer properties of GOF. A comparison between the performance of GOF and rGO membranes is reviewed in Lyu, Wen, Kumar, You, Chen, and Joshi (2017). ${ }^{67}$ The motivation for the utilization of rGO membranes is related to the primarily smaller pore size and interlayer spacing of rGO films compared to GO membranes, making rGO films potentially more suitable for desalination. While it has been extensively reported that the interlayer-spacing of pure GO laminates is $\sim 0.8 \mathrm{~nm}$, this value for rGO membranes was reported as $\sim 0.35 \mathrm{~nm} .{ }^{86}$ When tested in FO rGO membranes allow water permeation with high-salt rejection compared to GO membranes. ${ }^{68}$ Silver nanoparticle deposition on rGO laminates was shown to concurrently improve both biofouling resistance and ion rejection. ${ }^{68}$ rGO has shown higher than GO permeability and stability in water ${ }^{87}$ rGO combined with $\mathrm{TiO}_{2}$ and thin-film nanocomposite membrane has proven $99 \%$ salt rejection with $51.3 \mathrm{~L} \mathrm{~m}^{-2} \mathrm{~h}^{-1} \mathrm{bar}^{-1} .88$

To avoid interlayered structures, 3D GOF porous membranes have also been proposed, ${ }^{89}$ consisting of a complex 3D structure of oxidized graphene assembled in a randomly stacked pile, providing a complicated path to support filtration through micro and nanosieving processes for desalination and purification from salts to microbial pollutants, and dyes.
3.2.4 GOF with a porous support. GOF membranes can be fabricated using different porous support. One example is a GOmembrane on a highly porous polyacrylonitrile nanofibrous mat (GOPAN). ${ }^{\mathbf{9 0}}$ Fig. 3 presents a schematic illustration of the composite GOF membrane, showing hydrophilic 'gates' and hydrophobic nanochannels. ${ }^{90}$ GO flakes with large lateral size (more than $200 \mu \mathrm{m}$ ) are collected by vacuum filtration on an extremely porous nanofibrous mat. GO can form a filter with a controllable thickness on the top of a PAN nanofibrous mat. To explain the water diffusion mechanism through the GO layer, a hydrophilic-hydrophobic "gate"-nanochannel model is proposed, where hydrophilic gate permit the water to enter hydrophobic nanochannel letting the water molecules to flow between the closely-stacked GO nanosheets. Water flux increased significantly under 1 bar external pressure due to the GO layer and nanofibrous support. Finally, the GOPAN membrane shows a moderate rejection performance of $56.7 \%$ for $\mathrm{Na}_{2} \mathrm{SO}_{4}$, and $10 \%$ for $\mathrm{NaCl}$ with a flux of $8 \mathrm{~L} \mathrm{~m}^{-2} \mathrm{~h}^{-1} \mathrm{bar}^{-1}$.

GO nanosheets were deposited via an LBL assembly approach on polydopamine-coated polysulfone support and then cross-linked by 1,3,5-benzenetricarbonyl trichloride (TMC) providing a $58 \%$ salt rejection with $93.84 \mathrm{~L} \mathrm{~m}^{-2} \mathrm{~h}^{-1}$ bar $^{-1} \cdot{ }^{91,92}$

The properties of the substrates showed to have a remarkable influence on the adhesion and transport of GO membranes. In particular, the morphology and the chemical structure of the surface of the substrate permit the GO assembly and adhesion, while the pore structure of substrates governed the GO membrane transport resistance. Specifically, the PAN substrate possesses many oxidized functional groups that contribute to a robust adhesion with GO selective layer permitting the GO membrane to endure stability measurements for continuous operation over a long-period under high feed

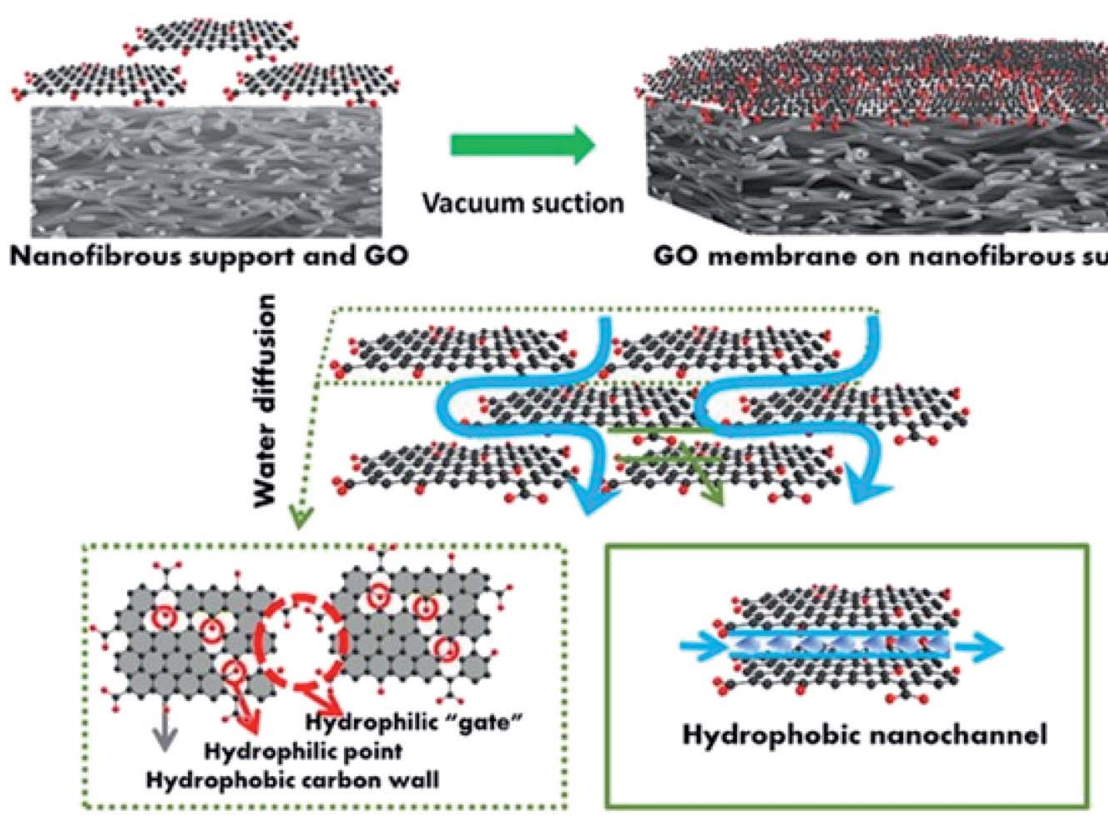

Fig. 3 Representation of the composite GO membrane, showing hydrophilic 'gates' and hydrophobic nanochannels. Reprinted (adapted) with permission from (Wang, J., Zhang, P., Liang, B., Liu, Y., Xu, T., Wang, L., Cao, B. \& Pan, K. Graphene oxide as an effective barrier on a porous nanofibrous membrane for water treatment. ACS Appl. Mater. Interfaces 8, 6211-6218 (2016) ${ }^{90}$ ). Copyright (2016) American Chemical Society. 
pressure. ${ }^{93}$ Therefore, PAN substrate smooth surface morphology and porous structure permit to achieve NF performance with a permeability of water of $15.5 \mathrm{~L} \mathrm{~m}^{-2} \mathrm{~h}^{-1} \mathrm{bar}^{-1}$ and with $99.5 \%$ rejection for dyes, while no information for salt rejection is provided.

Other types of supports were also used to make GO and rGO membranes such as $\mathrm{GO} /$ nylon providing a permeability of $71 \mathrm{~L}$ $\mathrm{m}^{-2} \mathrm{~h}^{-1}$ bar $^{-1}$ with $90 \%$ rejection for charged and uncharged organic probe molecules, while salt rejection is not mentioned. ${ }^{74}$

3.2.5 GO within a polymeric matrix. In addition to various support, another method consisted of incorporating GO nanosheets into a polymeric matrix. In Yin, Zhu, and Deng (2016) ${ }^{\mathbf{9 4}}$ GO nanosheets were incorporated in thin-film nanocomposite (TFN) membrane in the polyamide (PA) thin-film layer achieving $59 \mathrm{~L} \mathrm{~m}^{-2} \mathrm{~h}^{-1}$ bar $^{-1}$ with $94 \%$ of salt rejection.

An example of a composite GO membrane is based on GO deposited on the surface of poly(amide-imide)-polyethyleneimine (PAI-PEI) hollow fiber, obtaining a salt rejection of $48 \%$ and $5 \mathrm{~L} \mathrm{~m}^{-2} \mathrm{~h}^{-1}$ bar $^{-1}{ }^{95}$ Other nanocomposite GO membranes were fabricated showing high salt rejection above $98 \%$ with high permeability. ${ }^{\mathbf{8 8 , 9 6}}$

3.2.6 GO membranes selectivity limited by water instability issues. As one of the major issues found in GO membranes is their stability in water, ${ }^{97}$ studies have continued in the testing of GO membranes in a dead-end flow system. ${ }^{98}$ It was determined that salt rejection is not stable under pressure-driven conditions and prolonged testing time, as salt rejection plunged to 0 . Previously reported values of salt rejection are only the highest initial value for the specific test method. The effect inducing no salt rejection and loss of desalination was attributed to the metal cations in the salt solution, over time adsorbed on the GO membranes, and shielding the negative surface potential of the membrane. This result further strengthens the challenge of the application of GO membranes in a pressure-driven desalination system and requires reassessing the feasibility of GO membranes in desalination applications. A method for treatment of the surface charge in the GO membrane to realize a controllable ion transport was shown in Zhang et al. (2019). ${ }^{99}$

Realistic GO models from first principles MDS were established to study the stability of GO in water ${ }^{\mathbf{1 0 0}}$ and better explain the experiments of GOF in water. It was shown that GO in water has an unexpected mixture of hydrophilicity and fast water dynamics, with GO showing chemical activity in the water accumulating an average negative charge.

3.2.7 Strategies for stabilization of GO membranes in water. Due to the difficulty to stabilize GO membranes in water, an attempt to do so is reported in Zhang et al. $(2020)^{\mathbf{1 0 1}}$ via a socalled "molecular bridge strategy", in which an inter-laminar short-chain molecular bridge produces a robust GO laminate resistant to swell. A long-chain molecular bridge interfacing the substrate permits the GO laminate to better adhere to a porous substrate which can increase the mechanical strength of the membrane. By optimizing these molecular bridges, the GO membranes can display exceptional durability in severe operating conditions, such as high-pressure, cross-flow, and longterm filtration. This approach, which is scalable and can stabilize GO membranes, can be generalized to advance the reliability of atomic layers' laminar films for water environment applications.

Other methods to improve the stability of GO membranes in water were achieved by the simple addition of metal-cations to the planar laminate structure. ${ }^{\mathbf{1 0 2}}$

3.2.8 Hybrid GO membranes with other nanomaterials. Other types of GO membranes obtained as a hybrid with other nanomaterials have been considered, to combine the GO and other nanomaterials benefits for water desalination or purification. One example is the fabrication of a GO membrane based on quantum dots (GOQD). This membrane showed a pure water flux up to $23 \mathrm{~L} \mathrm{~m}^{-2} \mathrm{~h}^{-1}$ bar $^{-1}(0.2 \mathrm{MPa})$ with rejection to Congo red of $99.8 \%$, methylene blue of $97.6 \%$, while $66 \%$ for $\mathrm{Na}_{2} \mathrm{SO}_{4}$ and $17 \%$ for $\mathrm{NaCl}^{103}$

A hybrid GO and graphene membrane ${ }^{\mathbf{1 0 4}}$ was fabricated by spray coating an aqueous dispersion of $\mathrm{GO} /$ few-layered graphene/deoxycholate. The membranes were robust enough with a water flux of $17.3 \mathrm{~L} \mathrm{~m}^{-2} \mathrm{~h} \mathrm{bar}^{-1}$ while maintaining $\mathrm{NaCl}$ rejection near $85 \%$.

An NF membrane was fabricated by the synergic construction of GO and carbon nanotubes (CNTs), where the graphene properties of molecular filtering were used, while CNTs were intercalated between the GO adjacent layers to expand their interlayer space. The CNT-intercalated GO NF membrane (GOCNTm) exhibited a water flux up to $11.3 \mathrm{~L} \mathrm{~m}^{-2} \mathrm{~h}^{-1} \mathrm{bar}^{-1}$, more than twice that of the bare GO NF membrane (GOm), with high dye rejection ( $>99 \%$ for direct yellow and $>96 \%$ methyl orange). The GO-CNTm also showed good rejection rate for salt (i.e., $83.5 \%$ for $\mathrm{Na}_{2} \mathrm{SO}_{4}, 51.4 \%$ for $\left.\mathrm{NaCl}\right){ }^{105}$

It must be mentioned as some of the recent Monte-Carlo Simulations work ${ }^{\mathbf{1 0 6}}$ shows how the horizontal defects GOF stemming from the nonuniform deposition of the GO flakes during layers assembly are responsible for a decreased permeability of water as soon as the thickness increases due to an increased channels tortuosity. Also, these defects can facilitate salt percolation reducing the selectivity below 92\% with a permeability of water less than $1 \mathrm{~L} \mathrm{~m}^{-2} \mathrm{~h}^{-1} \mathrm{bar}^{-1}$. As such the performance of GOF should not be overestimated for separation when considering membranes thickness of 100 to $200 \mathrm{~nm}$.

\subsection{Graphene membranes of other designs, composite and hybrid}

GOF or rGO membranes' practical utilization as desalination membranes is hindered by numerous problems so far encountered during experiments, which comprise scalability issues for graphene mostly but also for printing of GOF, swelling of GO lamellar membranes' interlayer space, tortuosity, and mechanical and electro-chemical instability under typical pressure used in desalination approaches.

Novel GO membranes have been fabricated and more deep knowledge of these membranes has been achieved to overcome some of these issues.

Novel graphene and GO membrane design and process are proposed in Tománek, and Kyrylchuk (2019) ${ }^{\mathbf{1 0 7}}$ using ab initio calculations. The membrane core consists of highly oriented 
GO flakes sandwiched in between layers of buckypaper, consisting of quasi-one-dimensional graphitic carbon nanostructures including carbon nanotubes and carbon fibers, and an outmost layer made of strong carbon fabric. The carbon fabric is capable of withstanding extremely high pressures used in the RO process.

By embedding GO as a layer in cellulose triacetate (CTA) RO composite via the melting method, the hybrid membrane exhibited a higher permeation flux as compared to the original CTA RO membrane. ${ }^{108}$ By increasing the content of GO in the CTA RO membranes', their permeability increased from $1.67 \mathrm{~L}$ $\mathrm{m}^{-2} \mathrm{~h}^{-1}$ bar $^{-1}$ to $4.74 \mathrm{~L} \mathrm{~m}^{-2} \mathrm{~h}^{-1}$ bar $^{-1}$ while the salt rejection reduced at the same time, possibly caused by the formation of new channels offering a passage for saltwater.

Freestanding GO membranes were fabricated in Balapanuru et al. (2019), ${ }^{109}$ with a large-area (>1 $\mathrm{m}^{2}$ in the lab). To achieve high-performance in desalination the interlayer spacing of the GO sheets was controlled via partial oxidation. Partially oxidized few-layer GO performed much better compared to heavily oxidized GO in FO, primarily because of a smaller interlayer distance and reduced swelling. These membranes in FO show a $79 \mathrm{~L} \mathrm{~m}^{-2} \mathrm{~h}^{-1}$ bar $^{-1}$ water flux, $3.4 \mathrm{~g} \mathrm{~m}^{-2} \mathrm{~h}^{-1}$ reverse salt flux performs much better than that of commercial CTA membrane $\left(10 \mathrm{~L} \mathrm{~m}^{-2} \mathrm{~h}^{-1}\right.$ and $\left.12 \mathrm{~g} \mathrm{~m}^{-2} \mathrm{~h}^{-1} \mathrm{bar}^{-1}\right)$. Salt rejection studies on these membranes are not provided.

By changing the assembly GO nanoscrolls (GONS) made of GO sheets rolled into an open spiral coil assembly were proposed. ${ }^{110}$ The principle is to tailor each GONS to trap specific molecules and pollutants and form a membrane by stacking many of them LBL.

In the attempt to increase the scale of graphene membranes, large-area polycrystalline high strength metallurgical graphene was transferred onto polysulfone commercial MF membranes. To reduce the large defects generated during the transfer, GO, hydrazine, and/or nylon were used for sealing. GO in various types of configuration-with additional nanostructured hydrazine and/or nylon interfacial polymerization sealing-was prepared to obtain the best permeability of water and ions rejection rate. ${ }^{111}$ In FO, the salt rejection was from 60 to $95 \%$ (20\% from graphene without any further sealing), and the permeability of water from 5 to $24 \mathrm{ml} \mathrm{h}^{-1} \mathrm{~m}^{-2} \mathrm{bar}^{-1}$ depending on the membrane. ${ }^{\mathbf{1 1 1}}$ The optimal condition between the permeability of water and the rejection rate was obtained for membranes with G/GO/hydrazine (water flux of $15 \mathrm{ml} \mathrm{h}^{-1} \mathrm{~m}^{-2}$ bar $^{-1}$ and salt rejection $95 \%$ ). The permeability of water is one order of magnitude lower than for commercial RO membranes currently used. ${ }^{111}$ Functional GO membranes were fabricated, consisting of highly charged nanochannels produced in polyelectrolyte (PE) intercalated amine rGO membrane (PE@ArGO membrane). ${ }^{112}$ They provide $85 \%$ of salt rejection and water flux of $10.8 \mathrm{~L} \mathrm{~m}^{-2} \mathrm{~h}^{-1}$ bar $^{-1}$.112

Among the most promising achievement resides in graphene single-layer hybrid membrane with carbon nanotubes to provide mechanical stability. ${ }^{59}$

A composite GO/MXene membrane was fabricated showing enhanced performance in terms of an organic contaminant in water rejection and permeability, depending on the relative proportion of GO and MXene. A GO/MXene in a ratio 1/4 showed a greater water flux $\left(71.9 \mathrm{~L} \mathrm{~m}^{-2} \mathrm{~h}^{-1} \mathrm{bar}^{-1}\right)$ compared to a reference GO membrane $\left(6.5 \mathrm{~L} \mathrm{~m}^{-2} \mathrm{~h}^{-1} \mathrm{bar}^{-1}\right)$, with the GO/ MXene membrane showing excellent stability in water for over one month. The rejection of common small-molecule organic dyes was found to exceed $99.5 \%$. The higher water flow of the GO/MXene composite membrane compared to the reference GO membrane was mainly ascribed to the only minimal increase of interlayer spacing of the membrane due to the reduction of oxygen-containing functional groups. ${ }^{\mathbf{1 1 3}}$ Recently MXene has shown very promising properties for two-dimensional lamellar membrane for desalination with the highest water flux $>1000 \mathrm{~L}$ $\mathrm{m}^{-2} \mathrm{~h}$ bar $^{-1}$ for the MXene membrane supported by anodic aluminum oxide substrate. ${ }^{\mathbf{1 1 4}}$ Specifically, they achieved for example $22.4 \mathrm{~L} \mathrm{~m}^{-2} \mathrm{~h} \mathrm{bar}^{-1}$ for $\mathrm{NaCl}$ with a rejection of $55 \%$ with adjustable interlayer spacing. ${ }^{115}$ This value in terms of salt rejection and water flow is however not yet better than rGO modified by silver nanoparticles. ${ }^{68}$ A recent review of MXene for water desalination can be found in Ihsanullah (2020) ${ }^{\mathbf{1 1 6}}$ showing some promises as a novel lamellar membrane material.

\section{Graphene membranes applied processes}

The performance of a desalination system does not depend on the properties of the membrane only. The membrane is one component. Another important aspect is the process adopted to deliver desalinized water. Membrane and process are not yet a desalination system, that is much more complex, but it is the focus of this work to describe membranes and processes only. Graphene membranes based processed are grouped into four main categories,

(4.1) reverse osmosis (RO)

(4.2) forward osmosis (FO)

(4.3) distillation and pervaporation

(4.4) other processes including solar desalination specific.

\subsection{Reverse osmosis (RO)}

Membrane processes now dominate the desalination market (about 95\% in 2017). Reverse osmosis covers most of the market (about 55\% in 2019). Not a single product based on graphene is available on the desalination market, despite patents lodged as early as 2013 and then granted in 2014 by major companies of large financial capabilities. This prompts the question of why graphene-based membranes have not made their way to a product for RO desalination.

The expected novel generation membranes for water desalination are required with high selectivity and permeability, inexpensive, and fouling resistance.

As previously explained, graphene-based membranes are based on atomic layers with sub-nanometer pores providing in principle high flow rates of water with high selectivity. Similarly, lamellar GO or rGO has a high-water flow due to a combination of hydrophobic nanochannels formed between different GO layers and hydrophilic gates to enter the nanochannels, with the possibility to control the nanochannels size via inter-layers 

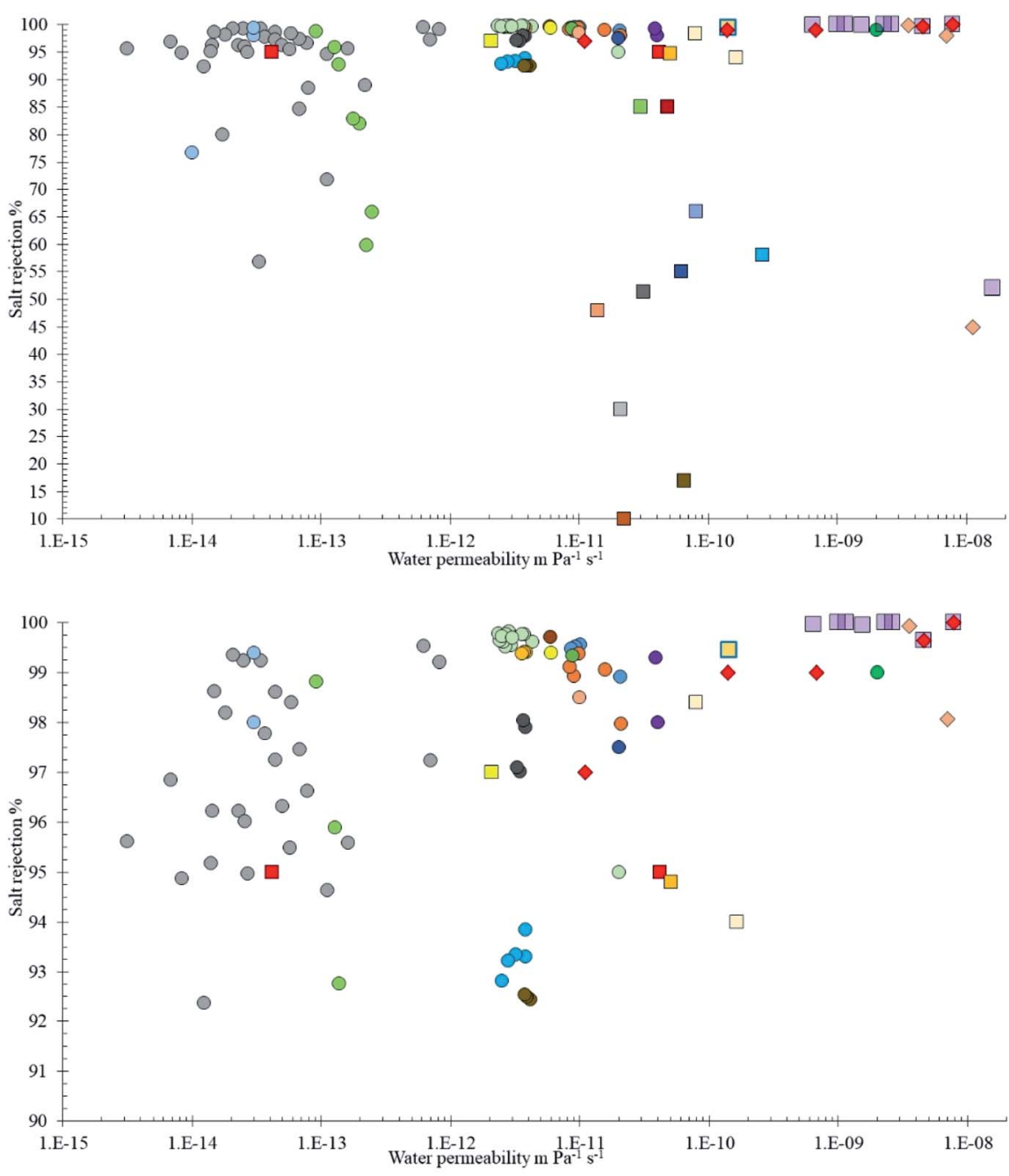

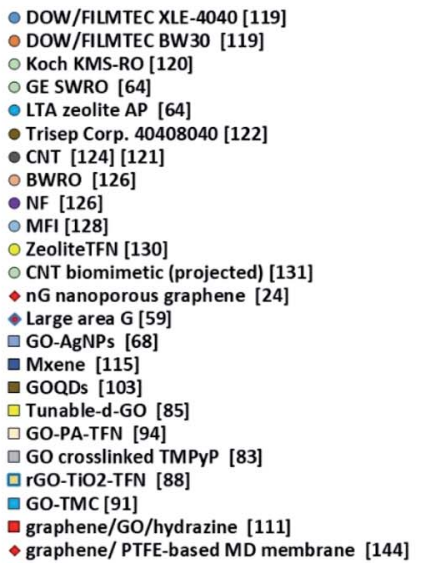

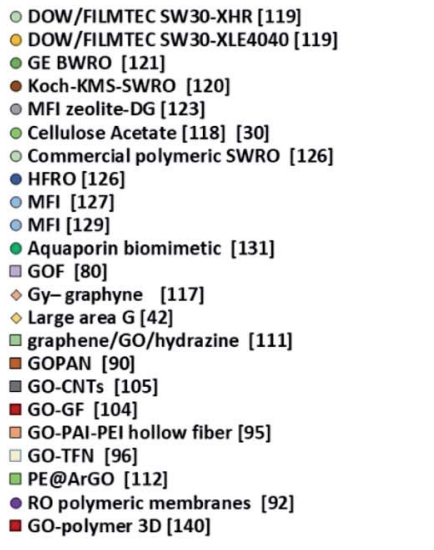

Fig. 4 Salt rejection versus permeability of various commercial and laboratory RO membranes represented with different colored circles, and graphene, GO and 2D materials single and multiple layers, hybrid and composited membranes represented by colored squares and diamonds. The operating conditions are in seawater - high-salinity or brackish - low-salinity conditions. Data are available from the listed references.

spacing. This is, however, difficult to realize in practice. Graphene membranes with pristine material with no morphological defects at an industrial scale needed for desalination are not yet available due to the fabrication limitation of both the perfect layer or of the on-demand pores with controlled sizes.
GO and rGO frameworks are suffering from instability in water due to swelling and difficulty to control the inter-layers spacing to provide the required selectivity and, apart from few examples, do not have better performance of currently used RO membranes. 
Fig. 4 summarizes the current performances of commercial and laboratory membranes, hydrophilic, and hydrophobic respectively. ${ }^{\mathbf{2 4 , 6 4 , 8 0 , 1 1 7 - 1 3 2}}$ A similar analysis is provided by Pendergast and Hoek (2011), ${ }^{\mathbf{1 1}}$ while here we add more recent examples of graphene and GO membranes for desalination. The highest selectivity with $>98 \%$ salt rejection is achieved by hydrophilic commercial membranes while the permeability is not very high in the range of (2 to 5$) \times 10^{-12} \mathrm{~m} \mathrm{~Pa}^{-1} \mathrm{~s}^{-1}$ for seawater and (2 to 6) $\times 10^{-11} \mathrm{~m} \mathrm{~Pa}^{-1} \mathrm{~s}^{-1}$ for brackish water. As opposite hydrophobic laboratory membranes provide permeability of $2 \times 10^{-10} \mathrm{~m} \mathrm{~Pa}^{-1} \mathrm{~s}^{-1}$ with however much lower salt rejection of 50 to $60 \%$. Results for $\mathrm{GOF}^{80}{ }^{\mathbf{N}} \mathrm{NPG},{ }^{24}$ and Gygraphyne $^{\mathbf{1 1 7}}$ and novel membranes more recently fabricated as hybrid or composite, described in the previous sections, are also summarized.

Graphene-based RO desalination membranes are predicted with almost complete salt rejection and permeability $10^{-9} \mathrm{~m}$ $\mathrm{Pa}^{-1} \mathrm{~s}^{-1}$. In some cases, very high permeability was measured $10^{-6} \mathrm{~m} \mathrm{~Pa}^{-1} \mathrm{~s}^{-1}$ and $99 \%$ salt rejection ${ }^{42}$ or $76 \%$ salt rejection. ${ }^{55}$ This was still for limited membrane areas, where the major problem remains to transfer large areas of single-layer graphene without introducing defects. Other single layers graphene membranes on a larger scale have provided a lower permeability $\left(10^{-11}\right.$ to $\left.10^{-10} \mathrm{~m} \mathrm{~Pa}^{-1} \mathrm{~s}^{-1}\right)$ with much better selectivity, ${ }^{56,59}$ indicating a better control of defects and stability of the membranes.

For what concerns GOF membranes various results have been shown, with salt rejection varying from 48 to $99 \%$, with best results for thin-film nanocomposite (TFN) membranes, ${ }^{\mathbf{8 8 , 9 6}}$ or hybrid GO membranes. ${ }^{104}$ The permeability is not yet better than $10^{-9} \mathrm{~m} \mathrm{~Pa}^{-1} \mathrm{~s}^{-1}, 88$ rather in the $10^{-11}$ to $10^{-10} \mathrm{~m} \mathrm{~Pa}^{-1} \mathrm{~s}^{-1}$, as such their performance, is marginally better than other RO polymeric membrane with $3.9 \times 10^{-11} \mathrm{~m} \mathrm{~Pa}^{-1} \mathrm{~s}^{-1} \cdot{ }^{92}$ Additional conditions must be fulfilled to appropriately compare these membranes with conventional RO desalination membranes.

For hydraulic pressure-driven processes, a membrane must satisfy criteria that in addition to selectivity and permeability, also encompass concentration polarization, and fouling; chemical and physical stability; economic and environmental cost. $^{\mathbf{1 0 , 3 0}}$ Current graphene-based membranes are still short of many of these above criteria. While the first two criteria could be fulfilled once scalability and stability in water could be achieved, concentration polarization and fouling will need to be assessed.

As previously discussed, improvements of current RO desalination systems in terms of energy consumption because of the reduced thickness of the graphene membranes is very difficult. This is because RO is currently close to the thermodynamic limit. ${ }^{26-28,133,134}$ This drastically limits the benefits of higher permeability membranes.

Since the energy needed for RO desalination is $\sim 2.2 \mathrm{~kW} \mathrm{~h}$ $\mathrm{m}^{-3}$, close to $\sim 1.8 \mathrm{~kW} \mathrm{~h} \mathrm{~m}^{-3}$ minimum work of $50 \%$ separation recovery, a more permeable membrane may only improve the energy demand by $\sim 10-20 \%$ with a cost reduction of $\sim 5-10 \%{ }^{10}$ As previously written, the RO process is thermodynamically limited. ${ }^{26-28,133,134}$ Thus, a higher-permeability desalination membrane introduced to reduce the pressure is of limited commercial advantage due to enough permeability of current membranes to meet low-energy demand. Energy savings could follow reducing concentration polarization ${ }^{30}$ causing fouling and flux decline.

In the last 3 years, ${ }^{11}$ the number of attempts to develop and prove new graphene-based desalination membranes for existing processes such as RO has reduced possibly because of the practical difficulties encountered. Tests of the above-described membranes in RO are very few. Most of the latest studies are simulations on the surface morphology of the GO membrane or interaction of GO membranes in water. ${ }^{\mathbf{1 0 0 , 1 3 5 , 1 3 6}}$ Many other latest works are reviews, ${ }^{13,35,78}$ or perspectives. ${ }^{137}$

Alternative and less common desalination processes together with further knowledge of basic phenomena that could lead to new processes have also been proposed. The new processes could circumvent some practical limitations experienced so far.

\subsection{Forward osmosis (FO)}

Graphene-based membranes have been mostly applied in FO rather than RO due to less pressure on the membrane, regardless of the initial aims to apply them in RO. FO relies on a separation process driven by the osmotic pressure across a semi-permeable membrane and it holds recognized advantages of high rejection efficiency, low irreversible membrane fouling, and less operational energy input. Compared to RO, FO is limited by the lack of appropriate membranes that solves the main issue which is internal concentration polarization (ICP).

An ideal FO membrane should retain the same characteristic as for RO which is a high water flux, rejection performance, and good mechanical strength to overcome natural osmotic pressure. TFC membranes developed for RO have been applied to FO, however, the permeability of these membranes is generally unsatisfactory under FO, and ICP is generally a serious drawback. Additionally, the selective thin PA layer of these membranes has a lower permeability in FO. Mixed Matrix Membranes and TFN membranes have been developed for FO with a variety of nanomaterials both in the selective thin layer and in the substrate. ${ }^{\mathbf{1 4}}$ TFC membranes and CTA commercial membranes used in FO have permeability $1 \div 3 \mathrm{~L} \mathrm{~m}^{-2} \mathrm{~h} \mathrm{bar}^{-1}$ and salt rejection $78 \div$ 94.5\% as reported by $\mathrm{Wu}$ et $a .^{14}$ and based on their references. Graphene and GO have found an opportunity to improve permeability in the TFC membranes for FO.

FO-graphene or GO enhanced membranes are used with a porous support membrane and their types can be divided into lamellar, surface modified, and blended membranes. In the lamellar type, the GO flakes are orderly stacked on top of the support and are the active layer where the separation is occurring. In the surface-modified, the flakes are on the surface either blended in the active selective layer (polyamide, PA) or on top of the active layer. In the last type, the membranes are made with GO blended in the porous support. ${ }^{14}$ The various membranes showed to enhance the permeability of water, reduce membrane fouling and reverse salt flux. These performances mainly depend on the type of membrane. As previously described, the lamellar layers of GO are obtained with LBL assembly, spin coating, vacuum filtration, and electrophoretic 
deposition, where electrostatic interaction and Van der Waals forces are inducing ordered stacks of GO flakes. Using electrophoretic deposition the FO membrane was fabricated by depositing the GO layer on the CNT hollow fiber membrane; chemical reduction of GO was performed to obtain rGO using hydriodic acid vapor. ${ }^{138}$ This rGO-CNT membrane achieved a water permeation of $22.6 \mathrm{~L} \mathrm{~m}^{-2} \mathrm{~h} \mathrm{bar}^{-1}$.

GO flakes are also blended with polysulfone (PSF) in the support layer, providing higher porosity, larger pore sizes, lower tortuosity, enhanced surface hydrophilicity, and improved structural properties without compromising the mechanical strength. ${ }^{139}$ Here the achieved water flux is $\sim 19.8 \mathrm{~L} \mathrm{~m}^{-2} \mathrm{~h} \mathrm{bar}^{-1}$. The performance of the PA active layer was modified by blending with GO the porous support, which has an increased surface roughness and surface area reaching water flux up to $\sim 37.7 \mathrm{~L} \mathrm{~m}^{-2} \mathrm{~h} \mathrm{bar}^{-1} \cdot{ }^{14}$ To reduce tortuosity, another limitation of GO membranes, 3D porous architecture with interconnected pores is constructed using a GO polymer composite membrane,${ }^{\mathbf{1 4 0}}$ which provides a direct pathway for water molecules to pass through. Here, FO water flux reaches $18.3 \mathrm{~L} \mathrm{~m}^{-2}$ $\mathrm{h}^{-1}$ and salt rejection of $94.8 \%$.

GO flakes were incorporated into the selective layer PA in the FO membrane to increase the membrane hydrophilicity and surface negative charge, resulting in enhanced separation, permeability, and improved antifouling property. ${ }^{\mathbf{1 4 1}}$

A similar effect was achieved by grafting the membrane surface by GO flakes acting as a new layer for the composite membrane adding better antifouling property and chlorine resistance ability. ${ }^{\mathbf{1 4 2}}$

The effect of a hydrophilic membrane surface due to GO is to delay the adsorption of proteins and/or lipids associated with the bacteria, to reduce the adhesion of hydrophobic bacteria, and to favor adhering of the water molecules via hydrogen bond. Also, functional groups such as carboxyl and hydroxyl in the GO nanosheets can strengthen the negative charge of the membrane surface inducing the electrostatic repulsion of negatively charged extracellular polymeric substance. ${ }^{\mathbf{1 4}}$

A study of the performances of GO flake lateral size on the PA active layer of the TFC membrane was completed. ${ }^{15}$ GO flakes average lateral size was ranging from 0.01 to $1.06 \mu \mathrm{m}^{2}$ and they were embedded in the PA layer to perform FO, showing an improvement in permeability and selectivity by $50 \%$ when the GO flakes area was reduced.

Based on all recent studies, the fabrication of an ultrathin GO lamellar FO membrane with the required mechanical strength and acquiring all the expected advantages of GO, remains a challenge, while the water permeability is improved compared to conventional membranes.

\subsection{Membrane distillation and pervaporation}

Graphene and GO membranes have seen recent applications in the MD desalination process, an emerging thermally driven water purification technology promising for the treatment of seawater, brine obtained from RO, industrial effluents. ${ }^{\mathbf{1 4 3}} \mathrm{MD}$ process consists of water purification driven by a vapor pressure gradient transversely a porous and hydrophobic membrane. It is used to harvest industry low-grade, solar, or waste heat for purification of concentrated salt solution from RO or FO processes. Generally, in the MD process, the membranes exhibit significant fouling behavior, rapidly and irreversibly degrading the membrane performance. As graphene is highly hydrophobic, its anti-fouling potential has been verified in an MD process based on a cm-scale chemical vapor deposited graphene with inherent nanochannels, then wet-transferred to a commercial polytetrafluoroethylene (PTFE) MD membrane. ${ }^{\mathbf{1 4 4}}$ Applying this membrane to seawater in direct contact $\mathrm{MD}$ (DCMD), the water flux was between $40-50 \mathrm{~L} \mathrm{~m}^{-2} \mathrm{~h}^{-1}{ }^{\circ} \mathrm{C}^{-1}$ for 72 hours and salt rejection in the range of $99 \%$, showing realworld applicability using the MD process. ${ }^{144}$ Besides exceptional antifouling properties were verified by rejecting common water-borne contaminants (i.e., oil and surfactants).

GO membranes were also applied in MD, intercalating GO flakes with $\mathrm{SiO}_{2}$ nanoparticles and further annealing to create hydrophobic membranes, showing salt rejection of $99.99 \%$ and water vapor flow of $13.59 \mathrm{~L} \mathrm{~m}^{-2} \mathrm{~h}^{-1}{ }^{\circ} \mathrm{C}^{-1} \cdot{ }^{16}$

Membranes with GO mixed with polysulfone (GO-PSF) were arranged by the wet-phase inversion method, ${ }^{17}$ using a GO of 0.25 to $2.0 \mathrm{wt} \%$. The membranes were used in DCMD with $\mathrm{NaCl}$ solutions concentration of $25000 \mathrm{mg} \mathrm{L}^{-1}$. The membranes that performed the best under RO distillate in terms of salt rejection and the porosity, included a content of $1.0 \mathrm{wt} \%$ GO. In these membranes, water fluxes of $20.8 \mathrm{~L} \mathrm{~m}^{-2} \mathrm{~h}^{-1}$ and $31.9 \mathrm{~L} \mathrm{~m}^{-2} \mathrm{~h}^{-1}$ were measured with $\mathrm{NaCl}$ solution and RO concentrate, respectively.

Pervaporation is a two steps separation process that includes permeation through the membrane by the permeate and evaporation into the vapor phase. During pervaporation one side of the membrane is in direct contact with the hot feed solution while on the other side where the permeate flow is exposed to a vacuum environment to remove it (see Fig. 4).

Pervaporation is an alternative process for liquid mixture separation by using nonporous membranes that could have benefits from the use of graphene or GO membranes. ${ }^{\mathbf{1 4 5}}$

GO composite membranes fabricated by filtration on different substrates were tested relatively to pervaporation desalination performance, ${ }^{\mathbf{1 4 6}}$ showing no dependence on the GO layer thickness, a stable desalination performance with 99.99\% salt rejection for over 50 hours of continuous brine desalination, and $67 \mathrm{~L} \mathrm{~m}^{-2} \mathrm{~h}^{-1}$ with $70{ }^{\circ} \mathrm{C}$ feed. It was determined that the transition of a liquid to vapor mainly took place at the top few layers of the GO laminates, and water transfer across the membrane occurred in their vapor form.

Due to high water flux and rejection rate, GO membranes if applied to pervaporation could provide an alternative approach to RO for water treatment with no liquid discharge and with the possibility to use waste or solar heat as an energy supply.

Fig. 5 presents a schematic diagram of GO pervaporation membranes for the brine desalination process.

\subsection{Other processes including solar desalination specific}

Specific solar desalination processes driven by sun energy differ from typical pressure-driven membrane processes. Due to the 


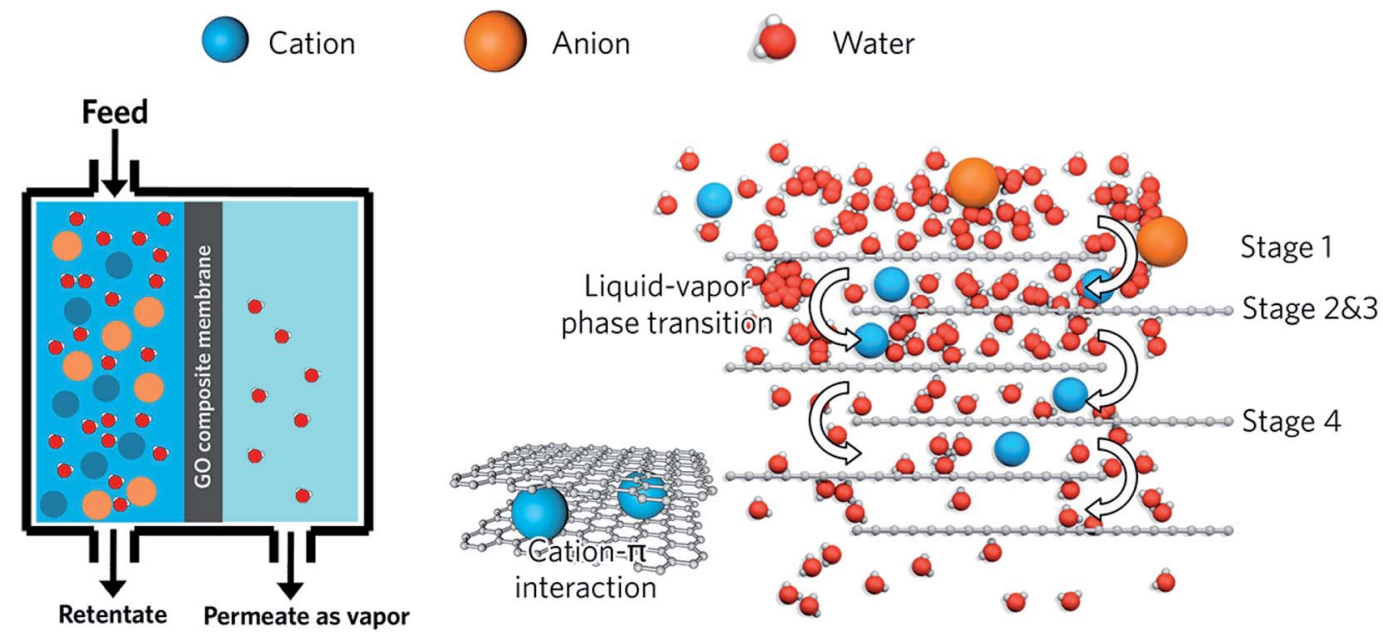

Fig. 5 Schematic diagram of the brine desalination process with the GO pervaporation membranes Reprinted (adapted) with permission from (Lin Li, Jingwei Hou, and Vicki Chen Industrial \& Engineering Chemistry Research, 2019, 58(10), 4231-4239. DOI: 10.1021/acs.iecr.8b06081). ${ }^{146}$ Copyright (2019) American Chemical Society.

mixture of both hydrophilic oxidized and hydrophobic pristine regions in GO, it can be applied to achieve acceleration in water evaporation as verified in pervaporation studies. This advantage can be adopted for desalination, steam generation, and other related industrial applications. An MDS study investigated the evaporation mechanism of water on an uneven GO surface. ${ }^{136}$ Solar energy as a low cost and environmentally friendly source of energy has been applied to desalination and combined with GO membranes. ${ }^{147}$ rGO membranes have also been applied in solar desalination processes. ${ }^{148}$

For example, a "bilayered biofoam" comprising a layer of bacterial nanocellulose (BNC) and a layer of BNC filled with rGO has been proposed in Jiang $(2016)^{149}$ for the production of steam by solar energy. The top of the membrane is the rGO-filled BNC layer that absorbs solar energy. The bottom of the membrane is the pristine BNC layer. Both these layers are permeable. The biofoam achieved a solar thermal efficiency of $\sim 83 \%$ under a simulated illumination of $10 \mathrm{~kW} \mathrm{~m}^{-2}$. The heat transfer to the bulk water underneath is minimized by the bottom layer.

An ultrathin rGO film was used as a solar absorber (absorption efficiency $>80 \%$ ) on a hydrophobic polytetrafluoroethylene (PTFE) membrane for water desalination via photothermal membrane distillation (PMD). Under standard solar illumination, the rGO-FTFE achieved a $78.6 \%$ enhancement of water flux if compared with the bare PTFE membrane. ${ }^{150}$ rGO design for membranes for solar thermal desalination is proposed in Meng and Li (2019). ${ }^{151}$

Solar driven desalination employing graphene is a fastgrowing subject with many other works worth consideration. ${ }^{152-154}$ As this review is focused on pressure-driven processes, this opportunity is here also mentioned without entering in too many details.

Additional to solar-driven, other processes are being considered as adopting graphene-based membranes.

Membrane crystallization ( $\mathrm{MCr}$ ) is considered an option to create the formation of crystals of salt from very high saline solutions such as seawater. MCr combines MD with crystallization. While MD produces water and concentrates the feed, crystallization induces crystals formation from supersaturated salts in the concentrated feed. In $\mathrm{MCr}$, a hydrophobic membrane is needed to remove the water in vapor form from a saline solution..$^{155}$ Composite polyvinylidene fluoride (PVDF) graphene membranes are proposed as cooperative interfaces for regulating nucleation-and-growth occurrence during the $\mathrm{MCr}$ process. ${ }^{156}$

Water permeation through membranes (mainly polymeric ones) can be controlled by modulating the structure of the membrane and the physicochemical properties of its surface as an example by varying the $\mathrm{pH}$, temperature, or ionic strength. This can be achieved by utilizing electrical control of the membrane to change water transport. By varying the electric field which ionizes water molecules inside graphene capillaries within the GO membranes ${ }^{157}$ the GO membranes' water transport was electrically controlled.

In regards to optimization of costs in water desalination due to membrane biofouling, $\mathrm{rGO}$, rGO-CuO, rGO-Ag, and $\mathrm{rGO}-$ $\mathrm{CuO}-\mathrm{Ag}$ films with antimicrobial properties were synthesized, evaluated, and tested showing good potentials to control or limit biofouling. ${ }^{158}$

\section{Discussion and conclusions}

This review has described the latest development of graphenebased membranes for desalination applications. The performance of different nanoporous graphene or stacked GO membranes has been described. Some new hybrid graphenebased membrane designs, such as using MXenes, ${ }^{113-116}$ GO quantum dots, ${ }^{113}$ carbon nanotubes ${ }^{105,107}$ have also been presented. The use of graphene nanomaterials in membranes for other desalination processes, such as membrane distillation and forward osmosis, was also examined. 
This review addresses the current need, challenges, and trends, potentially triggering a renewed interest in graphene membranes for yet unexplored approaches or other applications in membrane separation with high selectivity different from desalination. This review addresses a topic that has been extensively discussed in the literature, however suggesting a novel point. The actual research on making high-performance graphene membranes for desalination has paused in the RO direction, and it is seemingly evolving towards new directions.

Regarding the status outlined in Boretti et al. (2018), ${ }^{\mathbf{1 0}}$ graphene-based membranes have been further studied concerning their promises to turn into the favored contender for future membranes for desalination due to their high permeability and high selectivity. While graphene membranes possess very interesting performance for pressure-driven and osmoticdriven desalination processes, we still conclude that it remains difficult to scale them to the required real-world applications within these processes. Progress in scalability may be achieved by the direct formation of defective multilayer graphene on a porous support, for example, ceramic supports where pyrolysis in the presence of hydrogen has been used to convert chitosan into multilayer defective $\mathrm{B}$ and $\mathrm{N}$ doped graphene. ${ }^{159}$ Regarding GO and rGO membranes, while more scalable than graphene, contradictory results in applications in FO and RO osmosis indicate that the type of membranes and processes can provide a large range of water permeation and salt rejection values, not always better than other cutting-edge currently used membranes. Water stability in purely GO or rGO membranes seems to be still an open problem ${ }^{79,97,98}$ with however some possible solutions. ${ }^{79,101}$ GO membranes may be affected also by horizontal defects ${ }^{\mathbf{1 0 6}}$ arising from their layer by layer assembly. One of the yet unresolved issues in GO multilayered is the difficulty to control interlayer spacings, which can either limit selectivity if too large or the permeability if too narrow. Other methods to control the ions transport in the planar horizontal direction can be achieved using differently charged GO heterojunctions by applying an electric field, however, this is limited to small scale. ${ }^{\mathbf{1 6 0}}$ Composite GO membranes provide often relevant benefits in the performance compared to the same membrane without GO blend. ${ }^{\mathbf{8 8 , 9 4 9 6}}$ These novel membranes can be tolerant of chlorine, fouling and scaling, acid and base, ${ }^{158}$ and in some cases, also to oil and hydrocarbon $^{\mathbf{1 4 4}}$ and high temperature. Some studies are showing these potentials verified in composite membranes cases.

Based on this review, the performance of pure graphene membranes for desalinization is not meeting original expectations. Research on making high-performance graphene membranes for desalination appears much less active than before. None of the challenges previously identified ${ }^{\mathbf{1 0}}$ have been fully addressed and the potentials have not fully been exploited. The literature suggests the emerging of other less explored applications. Recent GO membranes provide better performances in $\mathrm{MD}^{\mathbf{1 6 , 1 7}}$ and pervaporation ${ }^{\mathbf{1 4 5 , 1 4 6}}$ desalination process, as well as in fouling reduction when combined with silver nanoparticles ${ }^{\mathbf{6 8}}$ and in thin-film nanocomposite membranes. ${ }^{\mathbf{8 8}}$ Applications in MD and pervaporation membranes and the role of graphene and GO in improving these processes is a promising direction, which certainly deserves more in-depth consideration.

\section{Author contributions}

Conceptualization, S. C. and A. B.; methodology, S. C. and A. B.; writing-original draft preparation, S. C. and A. B.; writingreview and editing, S. C. and A. B. All authors have read and agreed to the published version of the manuscript.

\section{Funding}

This research received no external funding.

\section{Conflicts of interest}

The authors declare no conflict of interest.

\section{References}

1 S. Homaeigohar and M. Elbahri, Graphene membranes for water desalination, NPG Asia Mater., 2017, 9, e427, DOI: 10.1038/am.2017.135.

2 Water, The United Nations world water development report 2019: water and energy, United Nations, Paris, 2019.

3 A. Aende, J. Gardy and A. Hassanpour, Seawater Desalination: A Review of Forward Osmosis Technique, Its Challenges, and Future Prospects, Processes, 2020, 8(8), 901, DOI: 10.3390/pr8080901.

4 Z. Li, A. Siddiqi, L. D. Anadon and V. Narayanamurti, Towards sustainability in water-energy nexus: ocean energy for seawater desalination, Renewable Sustainable Energy Rev., 2018, 82, 3833-3847, DOI: 10.1016/ j.rser.2017.10.087.

5 M. Qasim, M. Badrelzaman, N. N. Darwish, N. A. Darwish and N. Hilal, Reverse osmosis desalination: a state-of-theart review, Desalination, 2019, 459, 59-104, DOI: 10.1016/ j.desal.2019.02.008.

6 J. Kim, K. Park, D. R. Yang and S. Hong, A comprehensive review of energy consumption of seawater reverse osmosis desalination plants, Appl. Energy, 2019, 254, 113652, DOI: 10.1016/j.apenergy.2019.113652.

$7 \mathrm{~N}$. Voutchkov, Energy use for membrane seawater desalination-current status and trends, Desalination, 2018, 431, 2-14, DOI: 10.1016/j.desal.2017.10.033.

8 G. Amy, Membrane-based seawater desalination: present and future prospects, Desalination, 2017, 401, 16-21, DOI: 10.1016/j.desal.2016.10.002.

9 J. R. Werber, C. O. Osuji and M. Elimelech, Materials for next-generation desalination and water purification membranes, Nat. Rev. Mater., 2016, 1, 16018, DOI: 10.1038/natrevmats.2016.18.

10 A. Boretti, S. Al-Zubaidy, M. Vaclavikova, M. Al-Abri, S. Castelletto and S. Mikhalovsky, Outlook for graphenebased desalination membranes, npj Clean Water, 2018, 1, 5, DOI: 10.1038/s41545-018-0004-z. 
11 M. M. Pendergast and E. M. Hoek, A review of water treatment membrane nanotechnologies, Energy Environ. Sci., 2011, 4, 1946-1971, DOI: 10.1039/c0ee00541j.

12 A. Anand, B. Unnikrishnan, J.-Y. Mao, H.-J. Lin and C.-C. Huang, Graphene-based nanofiltration membranes for improving salt rejection, water flux and antifoulinga review, Desalination, 2018, 429, 119-133, DOI: 10.1016/ j.desal.2017.12.012.

13 E. Y. M. Ang, W. Toh, J. Yeo, R. Lin, Z. Liu, K. R. Geethalakshmi and T. Y. Ng, A review on low dimensional carbon desalination and gas separation membrane designs, J. Membr. Sci., 2020, 598, 117785, DOI: 10.1016/j.memsci.2019.117785.

14 W. Wu, Y. Shi, G. Liu, X. Fan and Y. Yu, Recent development of graphene oxide based forward osmosis membrane for water treatment: a critical review, Desalination, 2020, 491, 114452, DOI: 10.1016/j.desal.2020.114452.

15 N. Akther, Z. Yuan, Y. Chen, S. Lim, S. Phuntsho, N. Ghaffour, H. Matsuyama and H. Shon, Influence of graphene oxide lateral size on the properties and performances of forward osmosis membrane, Desalination, 2020, 484, 114421, DOI: 10.1016/ j.desal.2020.114421.

16 Y. Mao, Q. Huang, B. Meng, K. Zhou, G. Liu, A. Gugliuzza, E. Drioli and W. Jin, Roughness-enhanced hydrophobic graphene oxide membrane for water desalination via membrane distillation, J. Membr. Sci., 2020, 611, 118364, DOI: 10.1016/j.memsci.2020.118364.

17 L. M. Camacho, T. A. Pinion and S. O. Olatunji, Behavior of mixed-matrix graphene oxide - polysulfone membranes in the process of direct contact membrane distillation, Sep. Purif. Technol., 2020, 240, 116645, DOI: 10.1016/ j.seppur.2020.116645.

18 R. W. Baker, Membrane Technology and Applications, Sons, Hoboken, NJ, USA, 2012, DOI: 10.1002/9781118359686.

19 G. M. Geise, D. R. Paul and B. D. Freeman, Fundamental water and salt transport properties of polymeric materials, Prog. Polym. Sci., 2014, 39(1), 1-42, DOI: 10.1016/j.progpolymsci.2013.07.001.

20 Z. Zheng, R. Grünker and X. Feng, Synthetic TwoDimensional Materials: A New Paradigm of Membranes for Ultimate Separation, Adv. Mater., 2016, 28, 6529-6545, DOI: $10.1002 /$ adma.201506237.

21 P. S. Goh and A. F. Ismail, Graphene-based nanomaterial: the state-of-the-art material for cutting edge desalination technology, Desalination, 2015, 356, 115-128, DOI: 10.1016/j.desal.2014.10.001.

22 K. A. Mahmoud, B. Mansoor, A. Mansour and M. Khraisheh, Functional graphene nanosheets: the next generation membranes for water desalination, Desalination, 2015, 356, 208-225, DOI: 10.1016/ j.desal.2014.10.022.

$23 \mathrm{H}$. M. Hegab and L. Zou, Graphene oxide-assisted membranes: fabrication and potential applications in desalination and water purification, J. Membr. Sci., 2015, 484, 95-106, DOI: 10.1016/j.memsci.2015.03.011.
24 D. Cohen-Tanugi and J. C. Grossman, Water desalination across nanoporous graphene, Nano Lett., 2012, 12(7), 3602-3608, DOI: 10.1021/nl3012853.

25 D. Cohen-Tanugi and J. C. Grossman, Nanoporous graphene as a reverse osmosis membrane: recent insights from theory and simulation, Desalination, 2015, 366, 5970, DOI: 10.1016/j.desal.2014.12.046.

26 L. Song, Performance limitation of the full-scale reverse osmosis process, J. Membr. Sci., 2003, 214, 239-244, DOI: 10.1016/S0376-7388(02)00551-3.

27 A. Zhu, A. Rahardianto, P. D. Christofides and Y. Cohen, Reverse osmosis desalination with high permeability membranes-cost optimization and research needs, Desalin. Water Treat., 2010, 15(1-3), 256-266, DOI: 10.5004/dwt.2010.1763.

28 A. Zhu, P. D. Christofides and Y. Cohen, Effect of thermodynamic restriction on energy cost optimization of RO membrane water desalination, Ind. Eng. Chem. Res., 2009, 48(13), 6010-6021, DOI: 10.1021/ie800735q.

29 M. Elimelech and W. A. Phillip, The future of seawater desalination: energy, technology, and the environment, Science, 2011, 333, 712-717, DOI: 10.1126/science.1200488.

30 J. Imbrogno, J. J. Keating, J. Kilduff and G. Belfort, Critical aspects of RO desalination: a combination strategy, Desalination, 2017, 401, 68-87, DOI: 10.1016/ j.desal.2016.06.033.

31 F. Shao, C. Xu, W. Ji, H. Dong, Q. Sun, L. Yu and L. Dong, Layer-by-layer self-assembly $\mathrm{TiO} 2$ and graphene oxide on polyamide reverse osmosis membranes with improved membrane durability, Desalination, 2017, 423, 21-29, DOI: 10.1016/j.desal.2017.09.007.

32 Y. Cai and X. M. Hu, A critical review on draw solutes development for forward osmosis, Desalination, 2016, 391, 16-29, DOI: 10.1016/j.desal.2016.03.021.

33 M. Amjad, J. Gardy, A. Hassanpour and D. Wen, Novel draw solution for forward osmosis based solar desalination, Appl. Energy, 2018, 230, 220-231, DOI: 10.1016/ j.apenergy.2018.08.021.

34 R. L. McGinnis, N. T. Hancock, M. S. NowosielskiSlepowron and G. D. McGurgan, Pilot demonstration of the NH3/CO2 forward osmosis desalination process on high salinity brines, Desalination, 2013, 312, 67-74, DOI: 10.1016/j.desal.2012.11.032.

35 B. Al-Najar, C. D. Peters, H. Albuflasa and N. P. Hankins, Pressure and osmotically driven membrane processes: a review of the benefits and production of nano-enhanced membranes for desalination, Desalination, 2020, 479, 114323, DOI: 10.1016/j.desal.2020.114323.

36 A. Lee, J. W. Elam and S. B. Darling, Membrane materials for water purification: design, development, and application, Environ. Sci.: Water Res. Technol., 2016, 2, 1742, DOI: 10.1039/C5EW00159E.

37 K. S. Novoselov and A. Geim, The rise of graphene, Nat. Mater., 2007, 6, 183-191.

38 B. C. Brodie, On the atomic weight of graphite, Philos. Trans. R. Soc. London, 1859, 149, 249-259, DOI: 10.1098/ rstl.1859.0013. 
39 W. S. Hummers and R. E. Offeman, Preparation of graphitic oxide, J. Am. Chem. Soc., 1958, 80(6), 1339, DOI: 10.1021/ ja01539a017.

40 D. R. Dreyer, S. Park, C. W. Bielawski and R. S. Ruoff, The chemistry of graphene oxide, Chem. Soc. Rev., 2010, 39, 228-240, DOI: 10.1039/B917103G.

$41 \mathrm{X}$. Huang, Graphene-based materials: synthesis, characterization, properties, and applications, Small, 2011, 7(14), 1876-1902, DOI: 10.1002/smll.201002009.

42 S. P. Surwade, Water desalination using nanoporous singlelayer graphene, Nat. Nanotechnol., 2015, 10, 459-464, DOI: 10.1038/nnano.2015.37.

43 M. D. Fischbein and M. Drndić, Electron beam nanosculpting of suspended graphene sheets, Appl. Phys. Lett., 2008, 93, 113107, DOI: 10.1063/1.2980518.

44 Z. Bai, L. Zhang, H. Li and L. Liu, Nanopore Creation in Graphene by Ion Beam Irradiation: Geometry, Quality, and Efficiency, ACS Appl. Mater. Interfaces, 2016, 8, 2480324809, DOI: 10.1021/acsami.6b06220.

45 Y. Ying, Recent advances of nanomaterial-based membrane for water purification, Appl. Mater. Today, 2017, 7, 144-158, DOI: 10.1016/j.apmt.2017.02.010.

46 G. Liu, W. Jin and N. Xu, Graphene-based membranes, Chem. Soc. Rev., 2015, 44, 5016-5030, DOI: 10.1039/ C4CS00423J.

47 P. Sun, K. Wang and H. Zhu, Recent developments in graphene-based membranes: structure, mass-transport mechanism and potential applications, Adv. Mater., 2016, 28(12), 2287-2310, DOI: 10.1002/adma.201502595.

48 E. N. Wang and R. Karnik, Graphene cleans up water, Nat. Nanotechnol., 2012, 7, 552-554, DOI: 10.1038/ nnano.2012.153.

49 S. C. O'Hern, Selective molecular transport through intrinsic defects in a single-layer of CVD graphene, ACS Nano, 2012, 6(11), 10130-10138, DOI: 10.1021/nn303869m.

50 C. J. Russo and J. A. Golovchenko, Atom-by-atom nucleation and growth of graphene nanopores, Proc. Natl. Acad. Sci. U. S. A., 2012, 109(16), 5953-5937, DOI: 10.1073/ pnas.1119827109.

51 S. C. O'Hern, Selective ionic transport through tunable subnanometer pores in single-layer graphene membranes, Nano Lett., 2014, 14(3), 1234-1241, DOI: 10.1021/nl404118f.

52 S. C. O'Hern, Nanofiltration across defect-sealed nanoporous monolayer graphene, Nano Lett., 2015, 15(5), 3254-3260, DOI: 10.1021/acs.nanolett.5b00456.

53 K. Celebi, J. Buchheim, R. M. Wyss, A. Droudian, P. Gasser, I. Shorubalko, J.-I. Kye, C. Lee and H. G. Park, Ultimate Permeation Across Atomically Thin Porous Graphene, Science, 2014, 344(6181), 289-292, DOI: 10.1126/ science.1249097.

54 Y. Qin, Y. Hu, S. Koehler, L. Cai, J. Wen, X. Tan, W. L. Xu, Q. Sheng, X. Hou, J. Xue, et al., Ultrafast Nanofiltration through Large-Area Single-Layered Graphene Membranes, ACS Appl. Mater. Interfaces, 2017, 9, 9239-9244, DOI: 10.1021/acsami.7b00504.

55 A. S. Kazemi, S. M. Hosseini and Y. Abdi, Large total area membrane of suspended single layer graphene for water desalination, Desalination, 2019, 451, 160-171, DOI: 10.1016/j.desal.2017.12.050.

56 P. Cheng, M. M. Kelly, N. K. Moehring, W. Ko, A.-P. Li, J. C. Idrobo, M. S. H. Boutilier and P. R. Kidambi, Facile Size-Selective Defect Sealing in Large-Area Atomically Thin Graphene Membranes for Sub-Nanometer Scale Separations, Nano Lett., 2020, 20, 5951-5959, DOI: 10.1021/acs.nanolett.0c01934.

57 J. L. Achtyl, Aqueous proton transfer across single-layer graphene, Nat. Commun., 2015, 6, 6539, DOI: 10.1038/ ncomms7539.

58 S. Hu, M. Lozada-Hidalgo, F. C. Wang, A. Mishchenko, F. Schedin, R. R. Nair, E. W. Hill, D. W. Boukhvalov, M. I. Katsnelson, R. A. W. Dryfe, et al., Proton transport through one-atom-thick crystals, Nature, 2014, 516, 227230, DOI: 10.1038/nature14015.

59 Y. Yang, X. Yang, L. Liang, Y. Gao, H. Cheng, X. Li, M. Zou, R. Ma, Q. Yuan and X. Duan, Large-area graphenenanomesh/carbon-nanotube hybrid membranes for ionic and molecular nanofiltration, Science, 2019, 364, 1057, DOI: $10.1126 /$ science.aau5321.

60 M. Ma, G. Tocci, A. Michaelides and G. Aeppli, Fast diffusion of water nanodroplets on graphene, Nat. Mater., 2016, 15, 66-71, DOI: 10.1038/nmat4449.

61 T. Yang, H. Lin, K. P. Loh and B. Jia, Fundamental Transport Mechanisms and Advancements of Graphene Oxide Membranes for Molecular Separation, Chem. Mater., 2019, 31, 1829-1846, DOI: 10.1021/ acs.chemmater.8b03820.

62 D. Cohen-Tanugi, L. C. Lin and J. C. Grossman, Multi-layer nanoporous graphene membranes for water desalination, Nano Lett., 2016, 16(2), 1027-1033, DOI: 10.1021/ acs.nanolett.5b04089.

63 R. K. Joshi, Precise and ultrafast molecular sieving through graphene oxide membranes, Science, 2014, 343(6172), 752754, DOI: 10.1126/science.1245711.

64 R. R. Nair, H. A. Wu, P. N. Jayaram, I. V. Grigorieva and A. K. Geim, Unimpeded permeation of water through helium-leak-tight graphene-based membranes, Science, 2012, 335(6067), 442-444, DOI: 10.1126/science.1211694.

65 B. Mi, Graphene oxide membranes for ionic and molecular sieving, Science, 2014, 343(6172), 740-742, DOI: 10.1126/ science.1250247.

66 H. Huang, Z. Song, N. Wei, L. Shi, Y. Mao, Y. Ying, L. Sun, $\mathrm{Z}$. $\mathrm{Xu}$ and $\mathrm{X}$. Peng, Ultrafast viscous water flow through nanostrand-channelled graphene oxide membranes, Nat. Commun., 2013, 4, 2979, DOI: 10.1038/ncomms3979.

67 J. Lyu, X. Wen, U. Kumar, Y. You, V. Chen and R. K. Joshi, Separation and purification using GO and r-GO membranes, RSC Adv., 2018, 8, 23130-23151, DOI: 10.1039/C8RA03156H.

68 E. Yang, A. B. Alayande, C.-M. Kim, J.-h. Song and I. S. Kim, Laminar reduced graphene oxide membrane modified with silver nanoparticle-polydopamine for water/ion separation and biofouling resistance enhancement, Desalination, 2018, 426, 21-31, DOI: 10.1016/j.desal.2017.10.023. 
69 F. Perreault, A. Fonseca de Faria and M. Elimelech, Environmental applications of graphene-based nanomaterials, Chem. Soc. Rev., 2015, 44, 5861-5896, DOI: 10.1039/C5CS00021A.

$70 \mathrm{~J}$. Azamat, Functionalized graphene nanosheet as a membrane for water desalination using applied electric fields: insights from molecular dynamics simulations, $J$. Phys. Chem. C, 2016, 120(41), 23883-23891, DOI: 10.1021/ acs.jpcc.6b08481.

71 L. Najafi, R. Oropesa-Nuñez, B. Martín-García, F. Drago, M. Prato, V. Pellegrini, F. Bonaccorso and S. Bellani, Water-dispersible few-layer graphene flakes for selective and rapid ion mercury ( $\left.\mathrm{Hg}_{2}+\right)$-rejecting membranes, Mater. Adv., 2020, 1, 387-402, DOI: 10.1039/D0MA00060D.

72 H.-H. Huang, R. K. Joshi, K. K. H. De Silva, R. Badam and M. Yoshimura, Fabrication of reduced graphene oxide membranes for water desalination, J. Membr. Sci., 2019, 572, 12-19, DOI: 10.1016/j.memsci.2018.10.085.

73 J. Shen, Subnanometer two-dimensional graphene oxide channels for ultrafast gas sieving, ACS Nano, 2016, 10(3), 3398-3409, DOI: 10.1021/acsnano.5b07304.

74 A. Akbari, Large-area graphene-based nanofiltration membranes by shear alignment of discotic nematic liquid crystals of graphene oxide, Nat. Commun., 2016, 7, 10891, DOI: 10.1038/ncomms10891.

$75 \mathrm{Z}$. $\mathrm{Xu}$ and C. Gao, Aqueous liquid crystals of graphene oxide, ACS Nano, 2011, 5(4), 2908-2915, DOI: 10.1021/ nn200069w.

76 C. A. Amadei, I. Y. Stein, G. J. Silverberg, B. L. Wardle and C. D. Vecitis, Fabrication and morphology tuning of graphene oxide nanoscrolls, Nanoscale, 2016, 8, 67836791, DOI: 10.1039/C5NR07983G.

77 A. Ali, M. Aamir, K. H. Thebo and J. Akhtar, Laminar Graphene Oxide Membranes Towards Selective Ionic and Molecular Separations: Challenges and Progress, Chem. Rec., 2020, 20, 344-354, DOI: 10.1002/tcr.201900024.

78 S. Remanan, N. Padmavathy, S. Ghosh, S. Mondal, S. Bose and N. C. Das, Porous Graphene-based Membranes: Preparation and Properties of a Unique Two-dimensional Nanomaterial Membrane for Water Purification, Sep. Purif. Rev., 2020, 1-21, DOI: 10.1080/ 15422119.2020.1725048.

79 C. N. Yeh, K. Raidongia, J. Shao, Q. H. Yang and J. Huang, On the origin of the stability of graphene oxide membranes in water, Nat. Chem., 2014, 7, 166-170, DOI: 10.1038/ nchem.2145.

80 A. Nicolaï, B. G. Sumpter and V. Meunier, Tunable water desalination across graphene oxide framework membranes, Phys. Chem. Chem. Phys., 2014, 16, 86468654, DOI: 10.1039/c4cp01051e.

81 S. Zheng, Q. Tu, J. J. Urban, S. Li and B. Mi, Swelling of graphene oxide membranes in aqueous solution: characterization of interlayer spacing and insight into water transport mechanisms, ACS Nano, 2017, 11, 64406450, DOI: 10.1021/acsnano.7b02999.

82 W.-S. Hung, C.-H. Tsou, M. De Guzman, Q.-F. An, Y.-L. Liu, Y.-M. Zhang, C.-C. Hu, K.-R. Lee and J.-Y. Lai, Cross-linking with diamine monomers to prepare composite graphene oxide-framework membranes with varying d-spacing, Chem. Mater., 2014, 26, 2983-2990, DOI: 10.1021/ cm5007873.

83 X.-L. Xu, F.-W. Lin, Y. Du, X. Zhang, J. Wu and Z.-K. Xu, Graphene Oxide Nanofiltration Membranes Stabilized by Cationic Porphyrin for High Salt Rejection, ACS Appl. Mater. Interfaces, 2016, 8, 12588-12593, DOI: 10.1021/ acsami.6b03693.

84 L. Chen, G. Shi, J. Shen, B. Peng, B. Zhang, Y. Wang, F. Bian, J. Wang, D. Li, Z. Qian, et al., Ion sieving in graphene oxide membranes via cationic control of interlayer spacing, Nature, 2017, 550, 380-383, DOI: 10.1038/nature24044.

85 J. Abraham, K. S. Vasu, C. D. Williams, K. Gopinadhan, Y. Su, C. T. Cherian, J. Dix, E. Prestat, S. J. Haigh, I. V. Grigorieva, et al., Tunable sieving of ions using graphene oxide membranes, Nat. Nanotechnol., 2017, 12, 546-550, DOI: 10.1038/nnano.2017.21.

86 H. Liu, H. Wang and X. Zhang, Facile fabrication of freestanding ultrathin reduced graphene oxide membranes for water purification, Adv. Mater., 2015, 27(2), 249-254, DOI: 10.1002/adma.201404054.

87 K. H. Thebo, X. Qian, Q. Zhang, L. Chen, H.-M. Cheng and W. Ren, Highly stable graphene-oxide-based membranes with superior permeability, Nat. Commun., 2018, 9, 1486, DOI: 10.1038/s41467-018-03919-0.

88 M. Safarpour, A. Khataee and V. Vatanpour, Thin film nanocomposite reverse osmosis membrane modified by reduced graphene oxide/TiO2 with improved desalination performance, J. Membr. Sci., 2015, 489, 43-54, DOI: 10.1016/j.memsci.2015.04.010.

89 P. B. Pawar, S. Saxena, D. K. Badhe, R. P. Chaudhary and S. Shukla, 3D oxidized graphene frameworks for efficient nano sieving, Sci. Rep., 2016, 6, 21150, DOI: 10.1038/ srep21150.

90 J. Wang, P. Zhang, B. Liang, Y. Liu, T. Xu, L. Wang, B. Cao and K. Pan, Graphene Oxide as an Effective Barrier on a Porous Nanofibrous Membrane for Water Treatment, ACS Appl. Mater. Interfaces, 2016, 8, 6211-6218, DOI: 10.1021/acsami.5b12723.

$91 \mathrm{M}$. Hu and B. Mi, Enabling Graphene Oxide Nanosheets as Water Separation Membranes, Environ. Sci. Technol., 2013, 47, 3715-3723, DOI: 10.1021/es400571g.

92 C. Buelke, A. Alshami, J. Casler, J. Lewis, M. Al-Sayaghi and M. A. Hickner, Graphene oxide membranes for enhancing water purification in terrestrial and space-born applications: state of the art, Desalination, 2018, 448, 113132, DOI: 10.1016/j.desal.2018.09.008.

93 M. Zhang, J. Sun, Y. Mao, G. Liu and W. Jin, Effect of substrate on formation and nanofiltration performance of graphene oxide membranes, J. Membr. Sci., 2019, 574, 196-204, DOI: 10.1016/j.memsci.2018.12.071.

94 J. Yin, G. Zhu and B. Deng, Graphene oxide (GO) enhanced polyamide (PA) thin-film nanocomposite (TFN) membrane for water purification, Desalination, 2016, 379, 93-101, DOI: 10.1016/j.desal.2015.11.001. 
95 K. Goh, L. Setiawan, L. Wei, R. Si, A. G. Fane, R. Wang and Y. Chen, Graphene oxide as effective selective barriers on a hollow fiber membrane for water treatment process, $J$. Membr. Sci., 2015, 474, 244-253, DOI: 10.1016/ j.memsci.2014.09.057.

96 S. G. Kim, D. H. Hyeon, J. H. Chun, B.-H. Chun and S. H. Kim, Novel thin nanocomposite RO membranes for chlorine resistance, Desalin. Water Treat., 2013, 51, 63386345, DOI: 10.1080/19443994.2013.780994.

97 Z. Wang, F. He, J. Guo, S. Peng, X. Q. Cheng, Y. Zhang, E. Drioli, A. Figoli, Y. Li and L. Shao, The stability of a graphene oxide (GO) nanofiltration (NF) membrane in an aqueous environment: progress and challenges, Mater. Adv., 2020, 1, 554-568, DOI: 10.1039/D0MA00191K.

$98 \mathrm{R}$. Hu, G. Zhao, Y. He and H. Zhu, The application feasibility of graphene oxide membranes for pressuredriven desalination in a dead-end flow system, Desalination, 2020, 477, 114271, DOI: 10.1016/ j.desal.2019.114271.

99 M. Zhang, K. Guan, Y. Ji, G. Liu, W. Jin and N. Xu, Controllable ion transport by surface-charged graphene oxide membrane, Nat. Commun., 2019, 10, 1253, DOI: 10.1038/s41467-019-09286-8.

100 F. Mouhat, F.-X. Coudert and M.-L. Bocquet, Structure and chemistry of graphene oxide in liquid water from first principles, Nat. Commun., 2020, 11, 1566, DOI: 10.1038/ s41467-020-15381-y.

101 M. Zhang, Y. Mao, G. Liu, G. Liu, Y. Fan and W. Jin, Molecular Bridges Stabilize Graphene Oxide Membranes in Water, Angew. Chem., Int. Ed., 2020, 59, 1689-1695, DOI: 10.1002/anie.201913010.

102 K. Ching, B. Lian, G. Leslie, X. Chen and C. Zhao, Metalcation-modified graphene oxide membranes for water permeation, Carbon, 2020, 170, 646-657, DOI: 10.1016/ j.carbon.2020.08.059.

103 C. Zhang, K. Wei, W. Zhang, Y. Bai, Y. Sun and J. Gu, Graphene Oxide Quantum Dots Incorporated into a Thin Film Nanocomposite Membrane with High Flux and Antifouling Properties for Low-Pressure Nanofiltration, ACS Appl. Mater. Interfaces, 2017, 9, 11082-11094, DOI: 10.1021/acsami.6b12826.

104 A. Morelos-Gomez, R. Cruz-Silva, H. Muramatsu, J. OrtizMedina, T. Araki, T. Fukuyo, S. Tejima, K. Takeuchi, T. Hayashi, M. Terrones, et al., Effective $\mathrm{NaCl}$ and dye rejection of hybrid graphene oxide/graphene layered membranes, Nat. Nanotechnol., 2017, 12, 1083-1088, DOI: 10.1038/nnano.2017.160.

105 Y. Han, Y. Jiang and C. Gao, High-Flux Graphene Oxide Nanofiltration Membrane Intercalated by Carbon Nanotubes, ACS Appl. Mater. Interfaces, 2015, 7, 81478155, DOI: 10.1021/acsami.5b00986.

106 C. L. Ritt, J. R. Werber, A. Deshmukh and M. Elimelech, Monte Carlo Simulations of Framework Defects in Layered Two-Dimensional Nanomaterial Desalination Membranes: Implications for Permeability and Selectivity, Environ. Sci. Technol., 2019, 53, 6214-6224, DOI: 10.1021/ acs.est.8b06880.
107 D. Tománek and A. Kyrylchuk, Designing an All-Carbon Membrane for Water Desalination, Phys. Rev. Appl., 2019, 12, 024054, DOI: 10.1103/PhysRevApplied.12.024054.

108 K. Chen, C. Xiao, Q. Huang, H. Liu and Y. Tang, Fabrication and properties of graphene oxide-embedded cellulose triacetate RO composite membrane via melting method, Desalination, 2018, 425, 175-184, DOI: 10.1016/ j.desal.2017.10.004.

109 J. Balapanuru, K. K. Manga, W. Fu, I. Abdelwahab, G. Zhou, M. Li, H. Lu and K. P. Loh, Desalination properties of a freestanding, partially oxidized few-layer graphene membrane, Desalination, 2019, 451, 72-80, DOI: 10.1016/ j.desal.2018.08.005.

110 Z. Zhang, L. Zou, C. Aubry, M. Jouiad and Z. Hao, Chemically crosslinked rGO laminate film as an ion selective barrier of composite membrane, J. Membr. Sci., 2016, 515, DOI: 10.1016/j.memsci.2016.05.054.

111 G. Romaniak, K. Dybowski, A. Jeziorna, P. Kula and T. Kaźmierczak, Synthesis and characterization of semipermeable graphene/graphene oxide membranes for water desalination, J. Mater. Sci., 2020, 55, 9775-9786, DOI: $10.1007 / \mathrm{s} 10853-020-04648-w$.

112 X. Song, R. S. Zambare, S. Qi, B. N. I. L. Sowrirajalu, A. P. James Selvaraj, C. Y. Tang and C. Gao, Charge-Gated Ion Transport through Polyelectrolyte Intercalated Amine Reduced Graphene Oxide Membranes, ACS Appl. Mater. Interfaces, 2017, 9, 41482-41495, DOI: 10.1021/ acsami.7b13724.

113 T. Liu, X. Liu, N. Graham, W. Yu and K. Sun, Twodimensional MXene incorporated graphene oxide composite membrane with enhanced water purification performance, J. Membr. Sci., 2020, 593, 117431, DOI: 10.1016/j.memsci.2019.117431.

114 L. Ding, Y. Wei, Y. Wang, H. Chen, J. Caro and H. Wang, A Two-Dimensional Lamellar Membrane: MXene Nanosheet Stacks, Angew. Chem., Int. Ed., 2017, 56, 1825-1829, DOI: 10.1002/anie.201609306.

115 Y. Sun, S. Li, Y. Zhuang, G. Liu, W. Xing and W. Jing, Adjustable interlayer spacing of ultrathin MXene-derived membranes for ion rejection, J. Membr. Sci., 2019, 591, 117350, DOI: 10.1016/j.memsci.2019.117350.

116 I. Ihsanullah, Potential of MXenes in Water Desalination: Current Status and Perspectives, Nano-Micro Lett., 2020, 12, 72, DOI: 10.1007/s40820-020-0411-9.

117 J. Kou, X. Zhou, H. Lu, F. Wu and J. Fan, Graphyne as the membrane for water desalination, Nanoscale, 2014, 6, 1865-1870, DOI: 10.1039/C3NR04984A.

118 A. G. Livingston, Metal Organic Frameworks (MOFs) in Membranes for Organic Solvent Nanofiltration, Annual NAMS Confernce, Houston, TX, 2014.

119 P. Agre, Aquaporin water channels- from atomic structure to clinical medicine, J. Physiol., 2002, 109(11), 1395-1409, DOI: 10.1113/jphysiol.2002.020818.

120 C. Peter and G. Hummer, Ion transport through membrane-spanning nanopores studied by molecular dynamics simulations and continuum electrostatics 
calculations, Biophys. J., 2005, 89(4), 2222-2234, DOI: 10.1529/biophysj.105.065946.

$121 \mathrm{~J}$. K. Holt, Fast mass transport through sub-2-nanometer carbon nanotubes, Science, 2006, 312(5776), 1034-1037, DOI: $10.1126 /$ science.1126298.

122 L. Liu, Graphene oxidation: thickness-dependent etching and strong chemical doping, Nano Lett., 2008, 8(7), 19651970, DOI: 10.1021/nl0808684.

123 B. C. Robertson and A. L. Zydney, Protein adsorption in asymmetric ultrafiltration membranes with highly constricted pores, J. Colloid Interface Sci., 1990, 134(2), 563-575, DOI: 10.1016/0021-9797(90)90163-I.

124 A. Matin, Z. Khan, S. M. J. Zaidi and M. C. Boyce, Biofouling in reverse osmosis membranes for seawater desalination: phenomena and prevention, Desalination, 2011, 281, 116, DOI: 10.1016/j.desal.2011.06.063.

$125 \mathrm{M}$. Vert, Terminology for biorelated polymers and applications (IUPAC Recommendations 2012), Pure Appl. Chem., 2012, 84(2), 377-410, DOI: 10.1351/PAC-REC-10-1204.

126 G. Guillen and E. M. V. Hoek, Modeling the impacts of feed spacer geometry on reverse osmosis and nanofiltration processes, Chem. Eng. J., 2009, 149(1-3), 221-231, DOI: 10.1016/j.cej.2008.10.030.

127 L. Li, J. Dong, T. M. Nenoff and R. Lee, Desalination by reverse osmosis using MFI zeolite membranes, J. Membr. Sci., 2004, 243(1-2), 401-404, DOI: 10.1016/ j.memsci.2004.06.045.

128 L. Li, J. Dong and T. M. Nenoff, Transport of water and alkali metal ions through MFI zeolite membranes during reverse osmosis, Sep. Purif. Technol., 2007, 53(1), 42-48, DOI: 10.1016/j.seppur.2006.06.012.

129 N. Liu, L. Li, B. McPherson and R. Lee, Removal of organics from produced water by reverse osmosis using MFI-type zeolite membranes, J. Membr. Sci., 2008, 325(1), 357-361, DOI: 10.1016/j.memsci.2008.07.056.

130 M. L. Lind, D. Eumine Suk, T. V. Nguyen and E. M. Hoek, Tailoring the structure of thin film nanocomposite membranes to achieve seawater RO membrane performance, Environ. Sci. Technol., 2010, 44(21), 82308235, DOI: 10.1021/es101569p.

131 M. Kumar, M. Grzelakowski, J. Zilles, M. Clark and W. Meier, Highly permeable polymeric membranes based on the incorporation of the functional water channel protein Aquaporin Z, Proc. Natl. Acad. Sci. U. S. A., 2007, 104(52), 20719-20724, DOI: 10.1073/pnas.0708762104.

132 B. Corry, Designing carbon nanotube membranes for efficient water desalination, J. Phys. Chem. B, 2008, 112(5), 1427-1434, DOI: 10.1021/jp709845u.

133 W. Zhou, L. Song and T. K. Guan, A numerical study on concentration polarization and system performance of spiral wound RO membrane modules, J. Membr. Sci., 2006, 271(1-2), 38-46, DOI: 10.1016/j.memsci.2005.07.007.

134 A. Rahardianto, J. Gao, C. J. Gabelich, M. D. Williams and Y. Cohen, High recovery membrane desalting of lowsalinity brackish water: integration of accelerated precipitation softening with membrane RO, J. Membr.
Sci., 2007, 289(1-2), 123-137, DOI: 10.1016/ j.memsci.2006.11.043.

135 C. Sun, M. Liu and B. Bai, Molecular simulations on graphene-based membranes, Carbon, 2019, 153, 481-494, DOI: 10.1016/j.carbon.2019.07.052.

136 H. T. Kieu, K. Zhou and A. W.-K. Law, Surface morphology effect on the evaporation of water on graphene oxide: a molecular dynamics study, Appl. Surf. Sci., 2019, 488, 335-342, DOI: 10.1016/j.apsusc.2019.05.247.

137 R. Epsztein, R. M. DuChanois, C. L. Ritt, A. Noy and M. Elimelech, Towards single-species selectivity of membranes with subnanometre pores, Nat. Nanotechnol., 2020, 15, 426-436, DOI: 10.1038/s41565-020-0713-6.

138 X. Fan, Y. Liu and X. Quan, A novel reduced graphene oxide/carbon nanotube hollow fiber membrane with high forward osmosis performance, Desalination, 2019, 451, 117-124, DOI: 10.1016/j.desal.2018.07.020.

139 M. J. Park, S. Phuntsho, T. He, G. M. Nisola, L. D. Tijing, X.-M. Li, G. Chen, W.-J. Chung and H. K. Shon, Graphene oxide incorporated polysulfone substrate for the fabrication of flat-sheet thin-film composite forward osmosis membranes, J. Membr. Sci., 2015, 493, 496-507, DOI: 10.1016/j.memsci.2015.06.053.

140 D. Qin, Z. Liu, H. Bai and D. D. Sun, Three-dimensional architecture constructed from a graphene oxide nanosheet-polymer composite for high-flux forward osmosis membranes, J. Mater. Chem. A, 2017, 5, 1218312192, DOI: 10.1039/C7TA00741H.

141 Y. Li, Y. Yang, C. Li and L.-a. Hou, Comparison of performance and biofouling resistance of thin-film composite forward osmosis membranes with substrate/ active layer modified by graphene oxide, RSC Adv., 2019, 9, 6502-6509, DOI: 10.1039/C8RA08838A.

142 H. M. Hegab, A. ElMekawy, T. G. Barclay, A. Michelmore, L. Zou, C. P. Saint and M. Ginic-Markovic, Effective in situ chemical surface modification of forward osmosis membranes with polydopamine-induced graphene oxide for biofouling mitigation, Desalination, 2016, 385, 126137, DOI: 10.1016/j.desal.2016.02.021.

143 E. Drioli, A. Ali and F. Macedonio, Membrane distillation: recent developments and perspectives, Desalination, 2015, 356, 56-84, DOI: 10.1016/j.desal.2014.10.028.

144 D. H. Seo, S. Pineda, Y. C. Woo, M. Xie, A. T. Murdock, E. Y. M. Ang, Y. Jiao, M. J. Park, S. I. Lim, M. Lawn, et al., Anti-fouling graphene-based membranes for effective water desalination, Nat. Commun., 2018, 9, 683, DOI: 10.1038/s41467-018-02871-3.

145 K. Guan, G. Liu, H. Matsuyama and W. Jin, Graphene-based membranes for pervaporation processes, Chin. J. Chem. Eng., 2020, 28, 1755-1766, DOI: 10.1016/ j.cjche.2020.04.011.

146 L. Li, J. Hou and V. Chen, Pinning Down the Water Transport Mechanism in Graphene Oxide Pervaporation Desalination Membranes, Ind. Eng. Chem. Res., 2019, 58, 4231-4239, DOI: 10.1021/acs.iecr.8b06081.

147 X. Li, W. Xu, M. Tang, L. Zhou, B. Zhu, S. Zhu and J. Zhu, Graphene oxide-based efficient and scalable solar 
desalination under one sun with a confined 2D water path, Proc. Natl. Acad. Sci. U. S. A., 2016, 113, 13953, DOI: 10.1073/ pnas.1613031113.

148 Z. Pengyu, F. Hanyu, X. Ning, L. Bo, X. Jun and Z. Lin, Freestanding reduced graphene oxide (rGO) membrane for saltrejecting solar desalination via size effect, Nanophotonics, 2020, 9(15), 20200396, DOI: 10.1515/nanoph-2020-0396.

149 Q. Jiang, Bilayered biofoam for highly efficient solar steam generation, Adv. Mater., 2016, 28(42), 9400-9407, DOI: 10.1002/adma.201601819.

150 L. Huang, J. Pei, H. Jiang and X. Hu, Water desalination under one sun using graphene-based material modified PTFE membrane, Desalination, 2018, 442, 1-7, DOI: 10.1016/j.desal.2018.05.006.

151 Y. Meng and H. Li, Rational design of reduced graphene oxide film for solar thermal desalination, Water Supply, 2019, 19, 1704-1710, DOI: 10.2166/ws.2019.043.

152 C. Athanasekou, A. Sapalidis, I. Katris, E. Savopoulou, K. Beltsios, T. Tsoufis, A. Kaltzoglou, P. Falaras, G. Bounos, M. Antoniou and P. Boutikos, Mixed Matrix PVDF/Graphene and Composite-Skin PVDF/Graphene Oxide Membranes Applied in Membrane Distillation, Polym. Eng. Sci., 2019, 59(S1), E262-E278, DOI: 10.1002/ pen.24930.

153 T. Chen, A. Soroush and M. S. Rahaman, Highly Hydrophobic electrospun reduced graphene oxide/poly (vinylidene fluoride-co-hexafluoropropylene) membranes for use in membrane distillation, Ind. Eng. Chem. Res., 2018, 57(43), 14535-14543, DOI: 10.1021/acs.iecr.8b03584.

154 B. Gong, H. Yang, S. Wu, G. Xiong, J. Yan, K. Cen, Z. Bo and K. Ostrikov, Graphene array-based anti-fouling solar vapour gap membrane distillation with high energy efficiency,
Nano-Micro Lett., 2019, 11(1), 51, DOI: 10.1007/s40820019-0281-1.

155 B. K. Pramanik, K. Thangavadivel, L. Shu and V. Jegatheesan, A critical review of membrane crystallization for the purification of water and recovery of minerals, Rev. Environ. Sci. Bio/Technol., 2016, 15, 411439, DOI: 10.1007/s11157-016-9403-0.

156 M. L. Perrotta, F. Macedonio, E. Tocci, L. Giorno, E. Drioli and A. Gugliuzza, Graphene stimulates the nucleation and growth rate of $\mathrm{NaCl}$ crystals from hypersaline solution via membrane crystallization, Environ. Sci.: Water Res. Technol., 2020, 6, 1723-1736, DOI: 10.1039/C9EW01124B.

157 K. G. Zhou, K. S. Vasu, C. T. Cherian, M. Neek-Amal, J. C. Zhang, H. Ghorbanfekr-Kalashami, K. Huang, O. P. Marshall, V. G. Kravets, J. Abraham, et al., Electrically controlled water permeation through graphene oxide membranes, Nature, 2018, 559, 236-240, DOI: 10.1038/s41586-018-0292-y.

158 A. B. Alayande, C.-M. Kim, J. S. Vrouwenvelder and I. S. Kim, Antibacterial $\mathrm{rGO}-\mathrm{CuO}-\mathrm{Ag}$ film with contactand release-based inactivation properties, Environ. Res., 2020, 191, 110130, DOI: 10.1016/j.envres.2020.110130.

159 P. H. Presumido, A. Primo, V. J. P. Vilar and H. Garcia, Large area continuous multilayer graphene membrane for water desalination, Chem. Eng. J., 2020, 127510, DOI: 10.1016/j.cej.2020.127510.

160 Q. Wen, P. Jia, L. Cao, J. Li, D. Quan, L. Wang, Y. Zhang, D. Lu, L. Jiang and W. Guo, Electric-Field-Induced Ionic Sieving at Planar Graphene Oxide Heterojunctions for Miniaturized Water Desalination, Adv. Mater., 2020, 32, 1903954, DOI: 10.1002/adma.201903954. 